\title{
EL GÉNERO DROUETIUS MÉQUIGNON, 1942 STAT. PROM., DE LAS ISLAS AZORES (COLEOPTERA, CURCULIONIDAE, ENTIMINAE)
}

\author{
A. Machado*
}

\section{RESUMEN}

Drouetius Méquignon, 1942, establecido originalmente como subgénero monotípico de Laparocerus Schönherr, 1834, se eleva aquí a la categoría de género (stat. prom.) en base a datos morfológicos y moleculares. Se aporta una redescripción del género y de $D$. azoricus, y se describen $D$. azoricus nitens $\mathbf{n}$. ssp., $D$. azoricus parallelirostris n. ssp., D. azoricus separandus n. ssp., D. oceanicus $\mathbf{n}$. sp., D. oceanicus tristis n. ssp., D. borgesi n. sp., D. borgesi sanctimichaelis $\mathbf{n}$. ssp. y D. borgesi centralis $\mathbf{n}$. ssp. La configuración del transponedor del saco interno del edeago se ha empleado como criterio para agrupar las poblaciones insulares en una misma especie. Un test filogenético orientativo basado en secuencias parciales del gen mitocondrial 16SrRNA de especies representativas de varias de las tribus de Entiminae, apunta hacia una relación más estrecha entre Drouetius y Peritelus que con Brachyderes u otros géneros. Por último, se aporta una clave para la separación de las especies y subespecies, y se comentan su distribución insular y ecología en el archipiélago de las Azores, donde Drouetius es endémico.

Palabras clave: Taxonomía, nuevos taxones, islas Azores, Macaronesia, Drouetius, Laparocerus, Curculionidae, Entiminae.

\section{ABSTRACT}

The genus Drouetius Méquignon, 1942, stat. prom., from the Azores (Coleoptera, Curculionidae, Entiminae)

Drouetius Méquignon, 1942, was originally established as a monotypical subgenus of Laparocerus Schönherr, 1834, and is here upgraded to genus (stat. prom.) based on morphological and molecular data. The genus and D. azoricus are redescribed, and $D$. azoricus nitens $\mathbf{n}$. ssp., D. azoricus paralellirostris n. ssp. D. azoricus separandus $\mathbf{n}$. ssp., D oceanicus n. sp., D. oceanicus tristis n. ssp., D. borgesi $\mathbf{n}$. sp., D. borgesi sanctimichaelis $\mathbf{n}$. ssp., and D. borgesi centralis $\mathbf{n}$. ssp. are described. The different form of the transfer apparatus of the aedeagus has been used as criterion for aggregating the island populations into a single species. A tentative phylogenetic test based on partial sequences of the mitochondrial gene 16SrRNA from representative species of several tribes of Entiminae, points to a closer relationship between Drouetius and Peritelus, than with Brachyderes or other genera. Finally, a key for the identification of the species and subspecies is provided, as well as comments on their ecology and distribution in the Azores archipelago, where Drouetius is endemic.

Key words: Taxonomy, new taxa, Azores Islands, Macaronesia, Drouetius, Laparocerus, Curculionidae, Entiminae.

* c/ Chopin 1, 38208 La Laguna, Tenerife, Islas Canarias. Email. antonio.machado@telefonica.net 


\section{Introducción}

Las nueve islas Azores comprenden una superficie total de $2.523 \mathrm{~m}^{2}$ y están situadas a $38^{\circ} \mathrm{N}$ de latitud media y $28^{\circ} \mathrm{W}$ de longitud media en el Atlántico norte, a $3.200 \mathrm{~km}$ de América del Norte, a $1.250 \mathrm{~km}$ de Europa, y a $850 \mathrm{~km}$ de la isla de Madeira, hacia el sur. Todas las islas son de origen volcánico, abarcando desde los 8,2 millones de años de Santa María, la más vieja, a Pico, la más joven, con menos de 300.000 años (Azevedo \& Ferreira, 2006). Debido a su aislamiento, juventud geológica, reducido tamaño y clima oceánico húmedo, su fauna nativa -que es de origen paleártico, mayormente europeo- resulta bastante disarmónica y relativamente pobre si se la compara con la de los otros archipiélagos macaronésicos (Borges 1992). El último inventario faunístico compilado por Borges et al. (2005) lista 528 especies de coleópteros, de las cuales 66 son endémicas. Hay cuatro géneros exclusivos del archipiélago que además son monotípicos: Cedrorum Borges \& Serrano, 1993 (Carabidae), Pseudanchomenus Tarnier, 1860 (Carabidae), Crotchiella Israelson, 1985 (Cerambycidae) y Alestrus Ebert, 1942 (Elateridae). De las 55 especies de curculiónidos registrados, sólo 9 son endémicas.

Drouetius fue establecido por Méquignon (1942) como subgénero de Laparocerus Schönherr, 1834 para albergar a una única especie-Laparocerus azoricus Drouet, 1859- cuyas características no encajaban en ninguno de los subgéneros conocidos de Laparocerus de Canarias y Madeira. Desde su descripción hasta la fecha no se han incorporado nue- vas especies a Drouetius, mientras que L. azoricus se ha citado de todas las islas del archipiélago de las Azores, con la excepción de Santa María (Uyttenboogaart 1940, 1947; Roudier 1965; Serrano 1982; Borges 1990, 1991, 1992, 1993; Borges et al. 1989, 2000, 2005, 2006).

Machado et al. (2008), en un estudio molecular parcial del género Laparocerus basado en secuencias de nucleótidos de dos genes mitocondriales (citocromo oxidasa II y $16 \mathrm{~S}$ rRNA), revelan que existen dos clados, uno madeirense y otro canario, que conforman un grupo monofilético, mientras que Drouetius, exclusivo de las Azores, se separa considerablemente. En el filograma elaborado por estos autores, Drouetius se sitúa más próximo al grupo externo (Rhyncogonus excavatus de la Polinesia), que a los Laparocerus de Canarias y Madeira (ver distancias en la Tabla 1). Este resultado vino a corroborar la impresión previa, derivada del análisis morfológico, de que Drouetius es un género independiente que tiene poca relación con Laparocerus.

El propósito del presente trabajo es elevar Drouetius a rango de género, situarlo dentro de los Entiminae, completar su descripción genérica y dar a conocer dos nuevas especies que han pasado inadvertidas, así como establecer varias subespecies para las poblaciones insulares diferenciadas.

\section{Material y métodos}

El estudio morfológico se basa en material depositado en colecciones privadas y de varias ins-

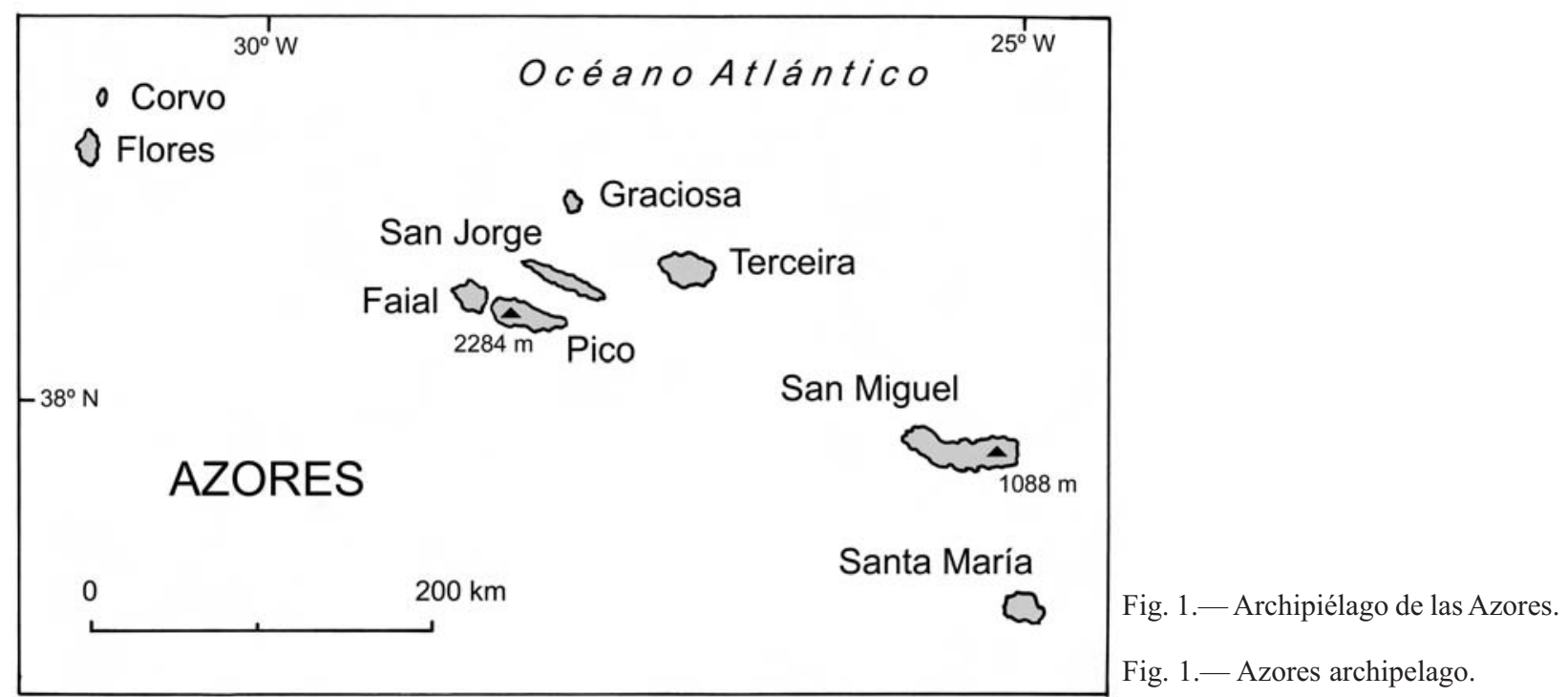

Graellsia, 65(1), Junio 2009, pp. 19-46 - ISSN: 0367-5041 
Tabla 1.- Distancias evolutivas corregidas, basadas en una secuencia parcial de nucleótidos de la citocromo oxidasa II. Datos tomados de Machado et al. (2008)

Tabla 1.- Corrected evolutive distances based on partial nucleotid sequences (598 bp) from mitochondrial cytochrome oxidase II gene. Data taken from Machado et al. (2008).

\begin{tabular}{lcccc}
\hline T a $\mathrm{x}$ a & Laparocerus canariensis & Laparocerus morio & Rhyncogonus excavatus & Drouetius azoricus \\
\hline Laparocerus morio, Madeira & 0,104 & & & \\
Rhyncogonus excavatus, Moorea & 0,174 & 0,220 & 0,249 & 0,039 \\
Drouetius azoricus, São Jorge & 0,297 & 0,272 & 0,240 & 0,279 \\
Drouetius borgesi, Terceira & 0,284 & & & \\
\hline
\end{tabular}

tituciones europeas, en el recolectado por el autor durante dos campañas realizadas en Julio de 2004 (Faial, Pico, Terceira, San Miguel y Santa María) y Junio de 2008 (Terceira y Faial), así como en el material obtenido durante el proyecto BALA (Biodiversity of Arthropods from the Laurisilva of the Azores) por el Dr Paulo A. V. Borges y su equipo del Departamento de Ciencias Agrarias de la Universidad de las Azores (Borges \& Serrano, 2000). El total de ejemplares estudiados asciende a 292, aunque 29 de ellos se han descartado por no disponer de datos sobre la isla de procedencia, o por ser ésta claramente errónea (p. ej. Madeira). Su desglose es como sigue: Corvo (22 exx), Flores (5 exx), Faial (37 exx), Pico (8 exx), San Jorge (14 exx), Graciosa (8 exx), Terceira (153 exx), San Miguel (16 exx). Los holotipos pertenecen o han sido depositados en instituciones públicas. Las siglas empleadas para referir a las diferentes colecciones son las siguientes:

AMC Antonio Machado Carrillo, colección privada. La Laguna, España.
DCA Departamento de Ciências Agrárias, Universidade dos Açores. Terceira, Portugal.

DEI Deutsches Entomologisches Institut. Müncheberg, Alemania.

GO Giuseppe Osella, colección privada. L'Aquila, Italia.

NHM The Natural History Museum. Londres, Reino Unido. MNHN Muséum National d'Histoire Naturelle. París, Francia. MHNT Museum d'Histoire Naturelle. Troyes, Francia.

NMW Naturhistorisches Museum Wien. Viena, Austria.

NRS Naturhistoriska Riksmuseet. Estocolmo, Suecia.

RB Roman Borovec, colección privada. Smidary, República Checa.

TFMC Museo de Ciencias Naturales. Santa Cruz de Tenerife, España.

ZMUH Zoological Museum, University of Helsinki, Finlandia.

Las disecciones fueron realizadas siguiendo los procedimientos entomológicos al uso. Para los dibujos se empleó una cámara clara montada sobre microscopio, y para las mediciones se utilizó una lupa binocular equipada con un micrómetro en el ocular. Las tallas se expresan en longitud del insecto, descontado el rostro. La convexidad de los ojos se indica dividiendo su altura (en vista dorsal) por el

Tabla 2.- Distancias simples en Drouetius basadas en una secuencia parcial de nucleótidos (598 pb) de la citocromo oxidasa II.

Tabla 2.- Pairwise distances based on partial nucleotid sequences (598 bp) from mitochondrial cytochrome oxidase II gene in Drouetius.

\begin{tabular}{lcccc}
\hline T a x a & $\begin{array}{c}\text { D. azoricus nitens } \\
\text { [COR] }\end{array}$ & $\begin{array}{c}\text { D. azoricus azoricus } \\
\text { [SJO] }\end{array}$ & $\begin{array}{c}\text { D. azoricus parallelirostris } \\
\text { [TER] }\end{array}$ & $\begin{array}{c}\text { D. borgesi centralis } \\
\text { [PIC] }\end{array}$ \\
\hline D. azoricus nitens & & & & \\
D. azoricus azoricus & 0,029 & & \\
D. azoricus parallelirostris & 0,045 & 0,046 & 0,125 & 0,021 \\
D. borgesi centralis & 0,097 & 0,075 & 0,119 & \\
D. borgesi borgesi $[\mathrm{TER}]$ & 0,086 & 0,070 & \\
\hline
\end{tabular}




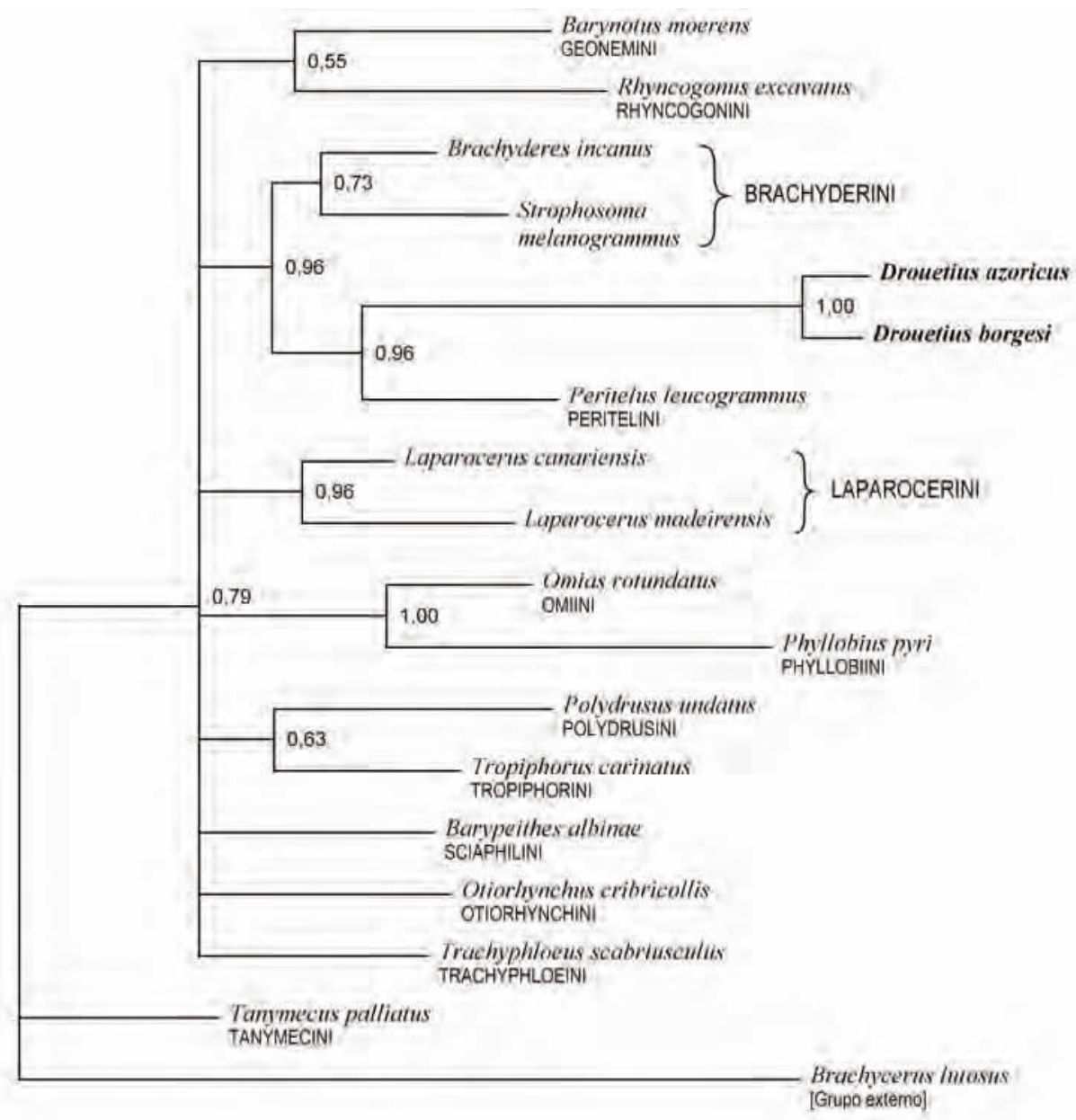

Fig. 2.- Especies representativas de tribus de Entiminae: filograma bayesiano de consenso ( $>50 \%$ ) para el 16SrRNA mostrando valores de probabilidad posterior.

Fig. 2- Representative species of tribes of Entiminae: Bayesian 50\% majority consensus phylogram for 16SrRNA showing posterior probability values.

eje mayor, obteniéndose un porcentaje que viene a representar la porción emergente de un teórico elipsoide o globo completo. Un $50 \%$, por ejemplo, equivaldría a un ojo sobresaliente, hemisférico; un 10\%, a un casquete muy reducido u ojo casi plano, etcétera. El término de prorrostro (Damoiseau, 1967) hace referencia a la parte anterior y dorsal del rostro delimitada por la línea donde usualmente se inicia el declive apical (justo detrás del nivel de inserción de las antenas); el metarrostro es la porción posterior, hasta su base. En relación con el órgano masculino, se introduce el término de "transponedor" para el transfer apparatus (s. Sharp, 1918), o pieza esclerificada donde termina el conducto seminal y por cuya punta, una vez evertida en la vagina de la hembra, salen los espermatóforos. La terminología de la espermateca corresponde a Thompson (1989).

Para obtener una idea aproximada de la ubicación del género Drouetius dentro del confuso conjunto de los Entiminae, se buscaron datos moleculares de especies pertenecientes a diferentes tribus en GenBank, localizándose secuencias parciales $(430 \mathrm{pb})$ del gen mitocondrial 16SrRNA de 

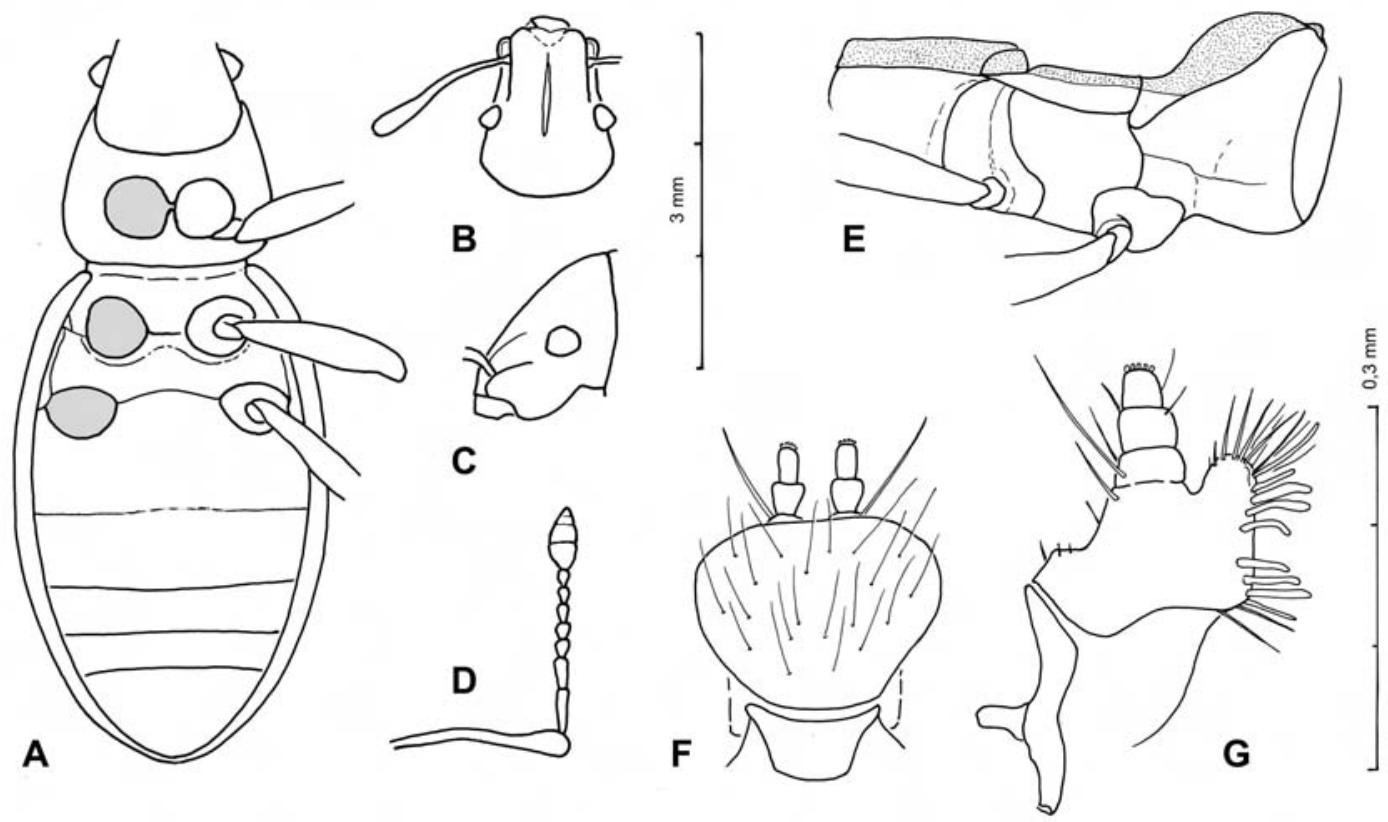

Fig. 3.-Drouetius oceanicus tristis n. ssp. Cara ventral (A), cabeza en vista dorsal (B) y lateral (C) y antena (D). Drouetius borgesi n.sp. Vista lateral del meso y metatorax (E), en punteado se marca el área cubierta por los élitros, mentón y prementón (F) y maxila $(G)$.

Fig. 3.- Drouetius oceanicus tristis n. ssp. Ventral parts (A), head in dorsal view (B) and in lateral view (C), and antenna (D). Drouetius borgesi n. sp. Lateral view of meso and metathorax (E) -dotted area is covered by elytra-, mentum and pre-mentum $(\mathrm{F})$, and maxilla (F).

representantes de 10 tribus, a las que se añadieron las de Laparocerini, Otiorhynchini y Rhyncogonini tomadas de Machado et al. (2008). El alineamiento múltiple se ejecutó con ClustalW (Thompson et al., 1994), luego ajustado a mano, y las relaciones filogenéticas se calcularon mediante inferencia bayesiana (Ronquist \& Huelsenbeck, 2003), aplicando el modelo evolutivo GTR $+\mathrm{I}+\mathrm{G}$ (seleccionado por MrModeltest 2.2), tras eliminar de la matriz las columnas con posiciones vacías. El filograma obtenido se representa en la figura 2; para su elaboración se eligió Brachycerus lutosus (Brachycerinae) como grupo externo.

Empleando las mismas técnicas que Machado et al. (2008) se han obtenido secuencias parciales del gen mitocondrial COII (598 pb) para dos taxones más (D. azoricus nitens y $D$. azoricus parallelirostris), pero lamentablemente no ha sido posible obtener material fresco de Drouetius oceanicus. Las distancias obtenidas se exponen en la Tabla 2 y se comentarán en la parte sistemática.

Los códigos de acceso de GenBank para las secuencias empleadas son: Barynotus moerens
(Fabricius, 1792) AJ495512, Barypeithes araneiformis (Schrank, 1781) AJ495500, Brachycerus lutosus Gyllenhal, 1833 AJ495597, Brachyderes incanus Flach, 1907 AJ495503, Drouetius azoricus azoricus (Drouet, 1859) (São Jorge) EF583417, Drouetius azoricus nitens n. ssp. (Corvo) FJ234427, Drouetius azoricus parallelirostris (Terceira) FJ234428, Drouetius borgesi borgesi n. spp. (Terceira) EF583418, Drouetius borgesi centralis n. ssp. (Pico) FJ234426, Laparocerus canariensis Boheman, 1842 EF583419, Laparocerus madeirensis Machado, 2008 EF583408, Omias rotundatus (Fabricius, 1792) AJ495515, Otiorhynchus cribricollis Gyllenhal, 1834 EF583436, Peritelus leucogrammus (Germar, 1824) AJ495484, Phyllobius pyri (Linnaeus, 1758) AJ495491, Polydrusus undatus (De Geer, 1775) AJ495496, Rhyncogonus excavatus Van Dycke, 1937 EF583435, Strophosoma melanogrammum (Forster, 1771) AJ495505, Tanymecus palliatus (Fabricius, 1787) AJ495507, Trachyphloeus scabriusculus (Linnaeus, 1771) AJ495516 y Tropiphorus carinatus Müller, 1776 AJ495488. 


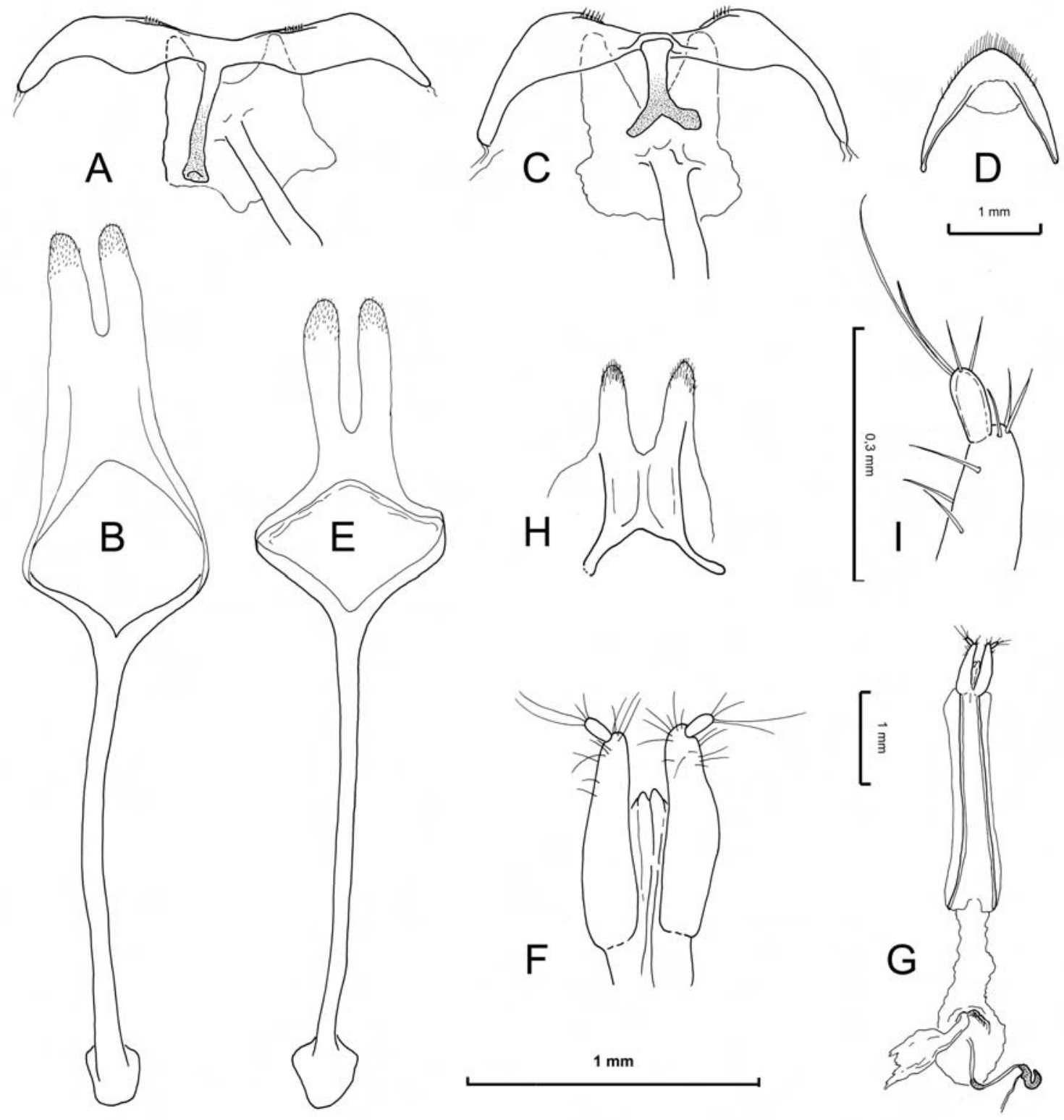

Fig. 4.- Drouetius borgesi n. sp., O7 de Terceira: urosternito VIII (A) y tegmen del edeago (B). Drouetius oceanicus tristis $\mathbf{n}$. ssp., de Graciosa: urosternito VIII masculino (C), uroterguito femenino (D), tegmen del edeago (E) y detalle de los hemisternitos femeninos (F). Drouetius oceanicus n. sp., de Terceira: genitalia femenina (G). Drouetius azoricus nitens n. ssp., de Flores: parámeros del tegmen (H). Drouetius azoricus azoricus, de San Jorge: estilo del hemisternito femenino )I).

Fig. 4.- Drouetius borgesi n. sp., O' from Terceira: urosternite VIII (A) and tegmen of aedeagus (B). Drouetius oceanicus tristis n. ssp., from Graciosa: male urosternite VIII (C), female uroterguite (D), tegmen of aedeagus (E), and detail of female hemisternites (F). Drouetius oceanicus n. sp., from Terceira: female genitalia (G). Drouetius azoricus nitens n. ssp. from Flores: tegmen parameres (H). Drouetius azoricus azoricus from San Jorge: stylus of female hemisternite (I). 


\section{Parte sistemática}

Género Drouetius Méquignon, 1942, status promotus

Laparocerus (Drouetius) Méquignon 1942a p. 10; Méquignon 1942 b p. 52; Alonso-Zarazaga \& Lyal 2000 p. 161; Machado et al. 2008 p. 422.

ESPECIE TIPO: Laparocerus azoricus Drouet, 1859 [designación original]

REDESCRIPCIÓN: Entiminos ápteros, de talla mediana (6,3-11,5 $\mathrm{mm})$, robustos, elongados y transversalmente convexos. Hembras más anchas y por lo general más grandes que los machos, y hombros más desarrollados.

Tegumentos oscuros, color de pez o pardo oscuro, notablemente punteados incluso en antenas y patas; revestimiento de pelitos o escamas lanceoladas abierto (no coalescente).

Cabeza robusta, de morro más o menos cuadrangular (Fig. 3A), estrangulado o no dorsalmente; prorrostro mal delimitado, sin quilla epistomal; metarrostro con márgenes laterales no levantados, surcado por una línea media incisa, eventualmente internada en la frente; sin fóvea frontal. Escrobas profundas, abiertas ampliamente hacia atrás, más o menos visibles desde arriba; pterigios breves, poco o moderadamente salientes, abiertos por delante. Mandíbulas cuadrangulares, cicatriz del apéndice mandibular caduco frontal y ligeramente pedicelada. Prementón plurisetulado, ancho, tapando lateralmente las maxilas (solo visible la base) (Fig. 3F).

Antenas fuertes y de talla mediocre; escapo con puntos longitudinales confluyentes, progresivamente engrosado desde la base y más o menos abruptamente capitado, hacia atrás alcanza el segundo cuarto pronotal; sinuoso en el tercio basal (en reposo, la sinuosidad contornea el ojo); funículo algo más largo que el escapo; primer desmómero más largo que el segundo; maza de 3 segmentos, ovalado-acuminada, algo comprimida, más o menos gruesa (Fig. 3D).

Pronoto dolioliforme, fuertemente punteado, más o menos estrechado por delante; reborde basal o a lo sumo en los lados (sobresale brevemente); reborde anterior liso y brillante, de anchura variable. Escudete triangular y visible; pre-scutum punteado.

Élitros oblongo-ovalados, más anchos que el pronoto, callos humerales algo desarrollados en las hembras; estrías poco o nada marcadas, intervalos con punteado fuerte, en ocasiones la superficie variolosa o subgranular (microescultura de celdas poligonales grandes e irregulares con un punto al centro).
Cara ventral (Fig. 3A): Procoxas más o menos contiguas, prosterno sin gránulo intercoxal posterior. Mesosterno y metasterno bastante planos en el disco, prácticamente al mismo nivel (declive anterior poco pronunciado), mesosterno entre las mesocoxas cuadrangular, totalmente plano y mitad de ancho que una mesocoxa; metacoxas alcanzando lateralmente el metepisterno, separación entre ellas más del doble que entre las mesocoxas; mesepímero visible; suturas mesopleurosternal y metapleurosternal bien definidas, metepímero diferenciado, oculto por el élitro (Fig. 3E). Esternitos abdominales punteados; $1^{\circ}$ y $2^{\circ}$ soldados en su tercio medio, la sutura más o menos desvanecida, ligeramente sinuosa; $2^{\circ}$ esternito tan largo como el $3^{\circ}$ y $4^{\circ}$ reunidos o el $5^{\circ}$; este último ligeramente más ojival en las hembras. Urosternito VIII masculino, estrecho (en forma de ave en vuelo), con proceso mediano semi-esclerotizado y breve (Figs. 4A y C).

Patas robustas, con seta trocanteral, sin dientes en los fémures; tibias sin crenulaciones, ni expansiones terminales, ni cepillos especiales, la pubescencia progresivamente más densa hacia el ápice, con cestilla abierta en la superficie articular apical, una fina seta terminal; protibias ligeramente arqueadas y anchas en la punta (particularmente en los machos), con tapiz apical de setas en la cara ventral (tipo almohadilla); meso y metatibias progresivamente ensanchadas hacia el ápice; tibias $\sigma^{\top} \sigma^{\top}$ mucronadas, en las 우 $ᄋ$ mucrón reducido o ausente en la metatibia y eventualmente en la mesotibia; tarsos anchos, triangulares, el IV ampliamente bilobulado; oniquio delgado, con uñas soldadas.

Genitalia masculina (Figs. 6-8): Lóbulo medio del edeago ancho y aplanado (como una canoa de fondo plano), arqueado, muy esclerotizado, con apertura apical hacia el frente; saco interno tubular y simple, hacia atrás (en reposo) menor o rebasando un poco los temones, con incipiente lígula apical, desprovisto de divertículos laterales, sin frenulum ni campos de dientes diferenciados (a lo sumo membranas escamosas tipo piel de serpiente o con dentículos separados); con transponedor en la parte distal bien desarrollado, formado por un conducto acanalado más o menos cerrado y retorcido, emplazado entre dos valvas de tamaño y forma variable; tegmen con parámeros anchos, cortos y provistos de flecos apicalmente, manubrio rematado en cabeza más o menos sagital (Figs. 4B y E).

Genitalia femenina: Ovopositor con dos estructuras baculiformes esclerotizadas a su largo (Fig. 4G); estilos cilíndricos, ligeramente subapicales, sobresalientes, con 4 setas terminales (Figs. 4F e I); spiculum ventrale con placa triangular estrecha y 
apodema rectilíneo (Fig. 9). Espermateca estrecha, de cola larga curvada y lóbulo glandular breve; ducto rígido más o menos esclerotizado y bruscamente ensanchado en su tramo medio o terminal (Fig. 11). Huevos muy oblongos, 2.7x más largos que anchos (Drouetius borgesi).

ObSERVACIONES: Drouetius fue descrito como subgénero de Laparocerus. Los ojos cónicos, moruloides, sobresalientes y excéntricos tan llamativos de D. azoricus hicieron postular a Uyttenboogaart (1947) una relación entre esta especie y Laparocerus (Guanchotrox) canariensis Boheman, 1842, que los tiene de igual forma. Sin embargo, esta carácter no se mantiene en Drouetius borgesi, en cuya subespecie nominotípica los ojos son uniformemente convexos y casi planos. Las diferencias estructurales entre Drouetius y Laparocerus son muchas e importantes. Drouetius tiene los tegumentos groseramente punteados, incluidas sus extremidades; el disco del mesosterno es bastante plano (declive anterior muy pronunciado en Laparocerus) y muy ancho -prácticamente cuadrangular- entre las coxas (estrecho y formando quilla o apófisis sobresaliente en Laparocerus); el primer esternito abdominal es plano en su tramo medio basal (no foveiforme) y está soldado al segundo esternito, con la sutura difuminada en el centro, y muy poco sinuosa. Además, carecen de fóvea frontal, el prementón es plurisetulado (ninguna o 2 setas en Laparocerus) y tapa prácticamente las maxilas; el ducto seminal de la espermateca está parcialmente esclerificado en el medio y el edeago carece de campos de dientes en el saco interno, pero presenta un transponedor muy característico, inexistente en Laparocerus. El esternito VIII persiste en los machos de Drouetius, portando una breve apófisis central mal esclerotizada (Figs. 4A, C), mientras que en Laparocerus no existe tal esclerito y solo queda en su sitio un spiculum relictum alargado y en forma de "Y" o doble "T", agarrado a la membrana. Los datos moleculares presentados por Machado et al. (2008) confirman el gran distanciamiento que existe entre Drouetius y Laparocerus.

Dentro de los curculiónidos, la sistemática de los Entiminae es caótica (Oberprieler et al., 2007), y numerosas tribus siguen aún mal delimitadas y pendientes de revisión. Dadas las características morfológicas de Drouetius, no es fácil atribuirlo a un grupo concreto. A Crotch (1867), la forma general del insecto le recuerda un Herpisticus (género endémico de Canarias, Tanymecini); consultado al respecto, R. Borovec (2007, com. pers.) descarta su adscripción a Omiini; y según las claves al uso,
Drouetius cae cerca de los Brachyderini. El pequeño test molecular realizado para ayudar a esclarecer estas cuestiones, apunta, sin embargo, a una relación más estrecha con Peritelus (Fig. 2) que con Brachyderes. Pese a ello, y dada la escasa información manejada (13 tribus de un total de 55, según Alonso-Zarazaga \& Lyal, 1999) lo prudente sería adscribir el género Drouetius a la tribu Peritelini a lo sumo con carácter provisional, so pena de dejarlo inserta saedis. Aunque las metaxocas están bastante separadas entre sí, y el acetábulo coxal metatorácico alcanza el margen lateral del metaesternito, como ocurre en Peritelini, Velázquez de Castro (com. pers. 2009) destaca discrepancias importantes: el ovopositor en esta tribu carece generalmente de estilos (e.g. Peritelus), la armadura del saco interno es compleja y corta (simple y alargada en Drouetius) y la lámina del octavo esternito de la hembra es ancha, con frecuencia hendida al ápice, en vez de estrecha y triangular.

Drouetius es un género endémico de las islas Azores con tres especies politípicas, cuya distribución se solapa parcialmente en el archipiélago. Por su morfología externa, Drouetius borgesi n. sp. se separa bien de las otras dos especies que son muy parecidas y se han venido confundiendo entre sí hasta el presente. La segregación en subespecies se fundamenta sobre todo en el punteado, la pubescencia, la forma de los ojos y la estructura del edeago. La agregación de las distintas poblaciones insulares subespecíficas en las tres especies reconocidas se basa en la tipología del transponedor del saco interno del edeago, que refleja tres modelos distintos e inconfundibles, pero sin descartar que alguna de ellas pudiera haber alcanzado el estatus de especie independiente. Los escasos datos moleculares disponibles corroboran, de momento, esta decisión.

Drouetius azoricus (Drouet, 1859)

(Figs. 4I, 5A, 6A, 9A, 10A, 11A y 12)

LOCALIDAD TíPICA: Camino de Horta a Caldeira en Faial.

Laparocerus azoricus Drouet 1859 p. 256.

Laparocerus (Atlantis) azoricus, in Lacordaire 1863 p. 200.

Laparocerus azoricus, in Crotch 1867 p. 388, pl. 23, fig. 6 [pars].

Laparocerus azoricus, in Winkler 1932 p. 1449.

Laparocerus azoricus, in Lona 1938 p. 436.

Laparocerus azoricus, in Uyttenboogaart 1940 p. 268 [pars].

Laparocerus azoricus, in Uyttenboogaart 1947 p. 8 [pars].

Laparocerus (Drouetius) azoricus, in Méquignon 1942 p. 52 [pars].

Laparocerus (Drouetius) azoricus, in Roudier 1965 p. 39 [pars?]. Laparocerus azoricus, in Serrano 1982 p. 90 [pars].

Laparocerus azoricus, in Borges \& Serrano 1989 p. 19 [pars]. 


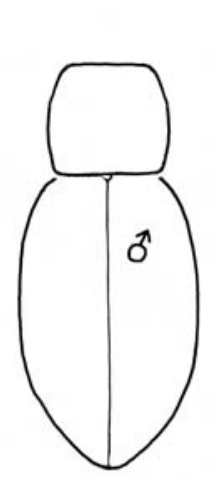

A
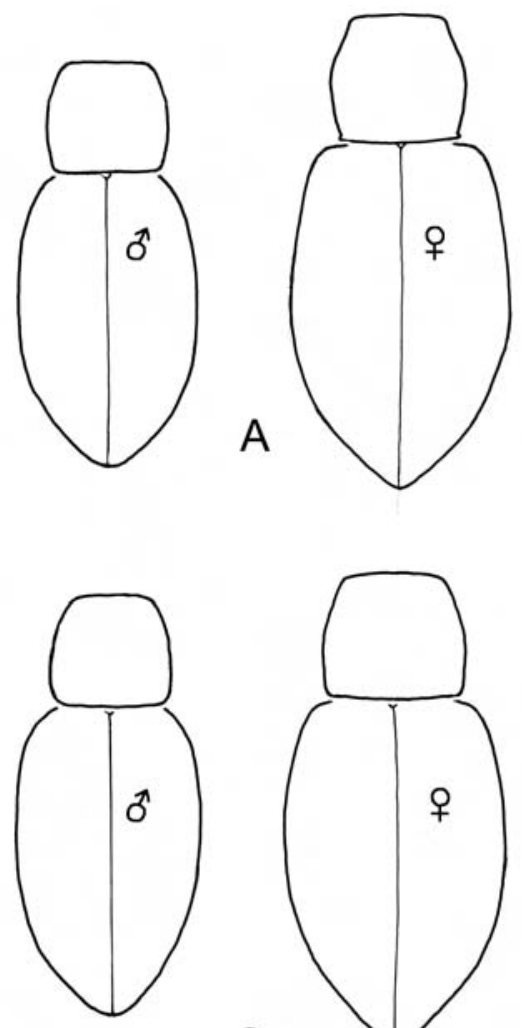

C

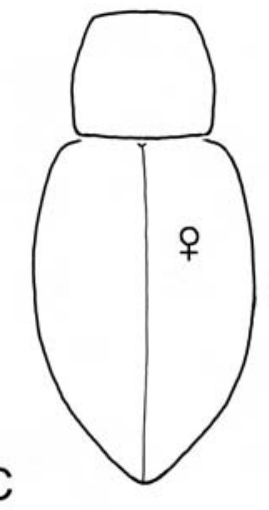

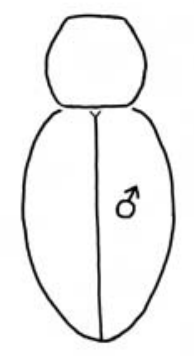

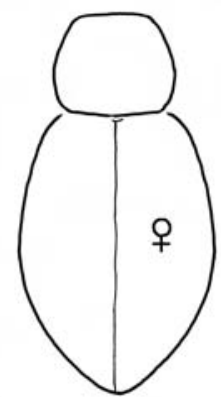

B
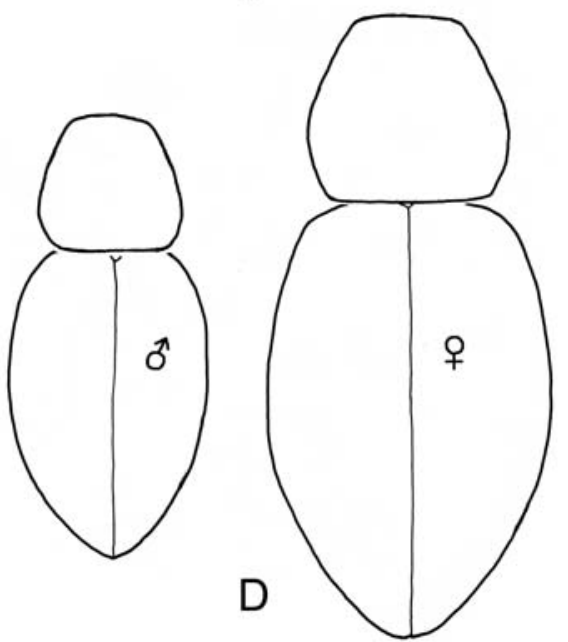

Fig. 5.- Silueta del macho y la hembra: Drouetius azoricus azoricus (A), Drouetius azoricus nitens n. ssp. (B), Drouetius oceanicus n. sp. (C) y Drouetius borgesi n. sp. (D).

Fig. 5.- Outline of male and female body: Drouetius azoricus azoricus (A), Drouetius azoricus nitens n. ssp. (B), Drouetius oceanicus n. sp. (C) and Drouetius borgesi n. sp. (D).

Laparocerus azoricus, in Borges 1992 p. 35 [pars].

Laparocerus azoricus, in Borges 2005 p. 201 [pars].

Laparocerus azoricus, in Machado 2006 p. 2007 [designación de lectotipo]

Laparocerus azoricus, in Machado et al. 2008 p 417 [ADN, San Jorge].

Material eXAMINADO: Faial: [Carretera de Horta a Caldeira] $10^{7}$ lectotipo (mihi), $2 \sigma^{\pi} \sigma^{\pi}$ y 3 \& $ᄋ$ paralectotipos [MayoSeptiembre 1857 leg. Drouet, ex litt.] (MHNT) [En la etiqueta del fondo de la caja reza: "Laparocerus Azoricus A. Drouet / Otiorrhynchus Hartungi Heer, Iles Açores". Este último nombre es inválido (nomen nudum, v. Machado, 2006)].- Horta, $2 \sigma^{7} \sigma^{7}$ 2 우 오, leg. Walker (NHM).- Sin localidad precisa: $10^{\pi}$ paralectotipo (mihi) ex Museum Guér-Menév (MNHN, Coll. Oberthur-Wollaston ); $1 \sigma^{\top} 1888$, leg. de Guerne (MNHN), 2 우 우 7-1939 leg. K. Byström (NRS). San Jorge: Gruta da Presa do Leão. 2 ㅇ ㅇ , 8-2000, leg. P. Borges, (AMC) + GeneBank EF583348 (COII) EF583417 (16sRNA). Graciosa: [sin localidad precisa] $10^{\top} 2$ 우 우, 1888 [leg.. de Guerne] (MNHN, Coll. Ch. Alluaud).- Pico Timão, 1 ㅇ 20-8-1987, leg. P. Borges (DCA).
REDESCRIPCIÓN (ssp. azoricus). Machos: Talla: 7,0-8,2 $\mathrm{mm}$. Insecto oblongo; tegumento subnítido de color negro de pez, fuertemente punteado. Pubescencia dorada, rala y breve, más larga y densa en los flancos.

Cabeza robusta; rostro breve, cuadrangular, no estrangulado dorsalmente, fuertemente punteadoruguloso (longitudinalmente), apenas deprimido; surco medio amplio y profundo a todo lo largo del prorrostro y extendido por la frente; márgenes ventrales convergentes hacia la base; pterigios claramente sobresalientes.

Ojos cónicos, moruloides, salientes (convexidad $45 \%$ ), su cenit desplazado hacia atrás, emplazados a media altura en la cabeza.

Antenas robustas; escapo fuertemente punteado (puntos confluentes), tan largo como el pronoto, funículo más largo que la longitud del pronoto; des- 

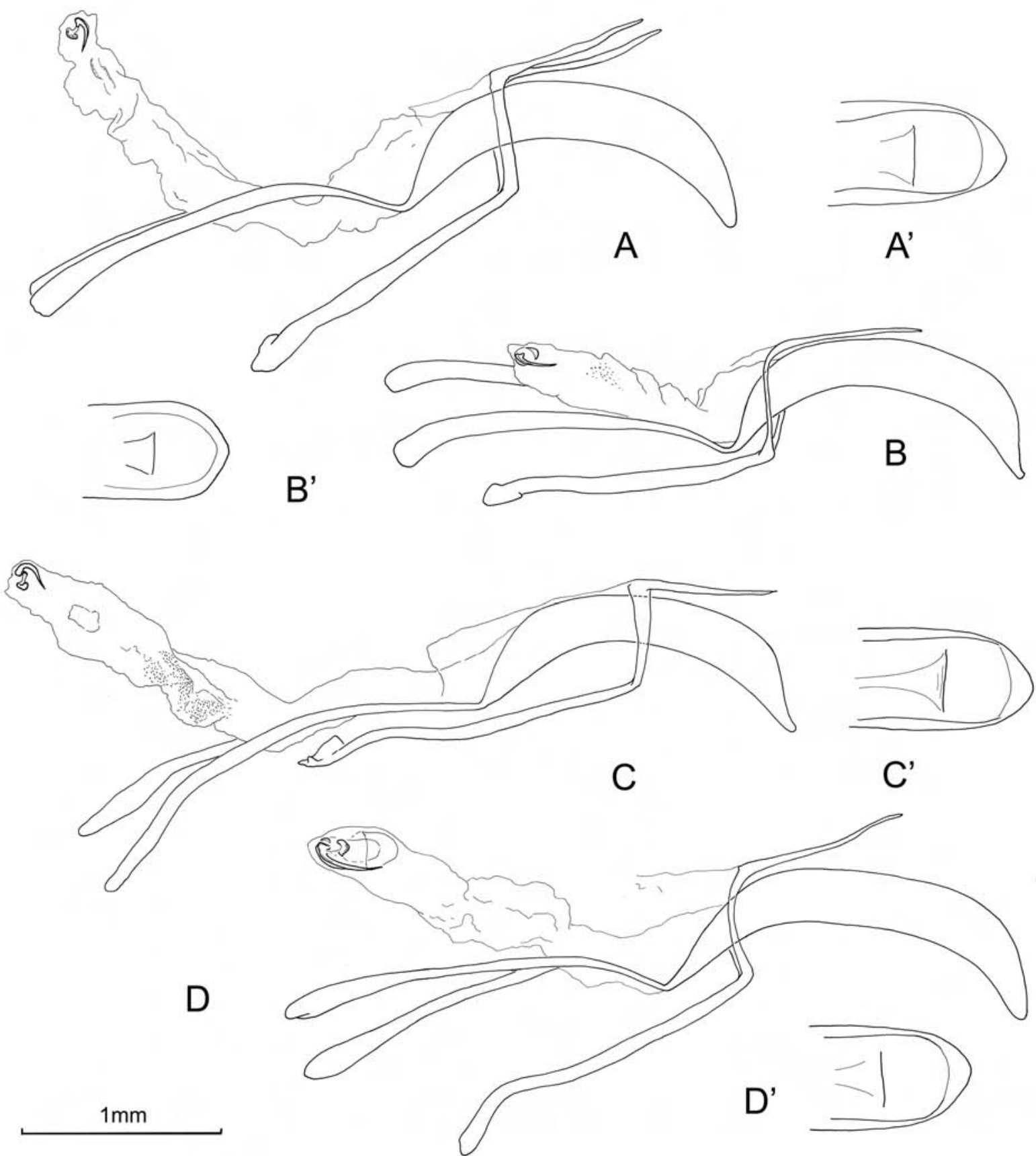

Fig. 6.- Edeago y detalle del ápice del lóbulo medio: Drouetius azoricus azoricus, de Faial (A-A'), Drouetius azoricus nitens $\mathbf{n}$. ssp., de Flores (B-B'), Drouetius azoricus parallelirostris n. ssp., de Terceira (C-C') у Drouetius azoricus separandus n. ssp., de San Miguel (D-D').

Fig. 6.- Aedeagus and detail of median lobe apex: Drouetius azoricus azoricus, de Faial (A-A'), Drouetius azoricus nitens n. ssp., from Flores (B-B'), Drouetius azoricus parallelirostris n. ssp., from Terceira (C-C') and Drouetius azoricus separandus n. ssp., from San Miguel (D-D'). 

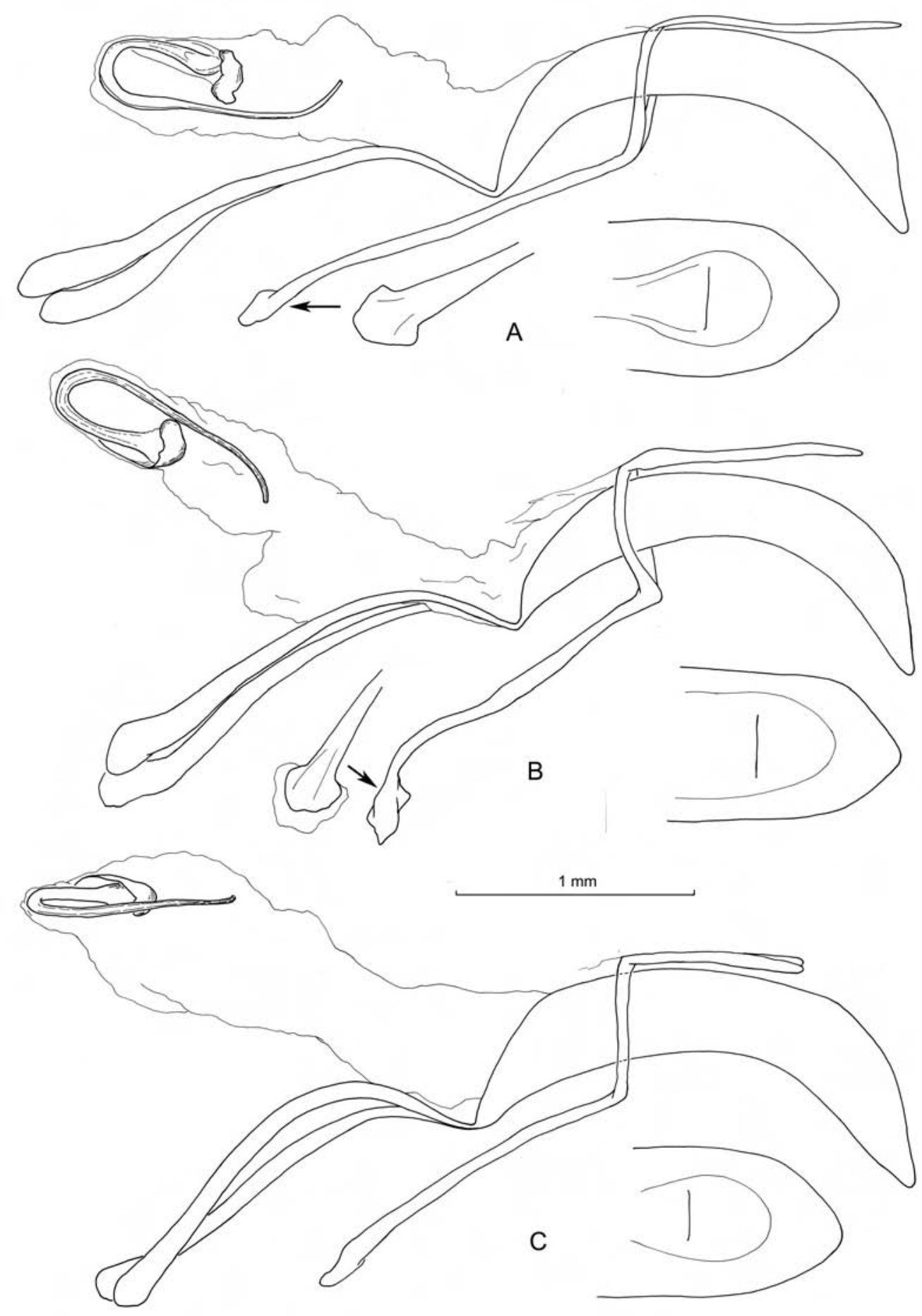

Fig. 7.- Edeago y detalle del ápice del lóbulo medio: Drouetius oceanicus n. sp., de Terceira (A), Drouetius oceanicus tristis n. ssp. de Faial (B) y de Graciosa (C).

Fig. 7.- Aedeagus and detail of median lobe apex: Drouetius oceanicus n. sp., from Terceira (A), Drouetius oceanicus tristis n. ssp. from Faial (B), idem from Graciosa (C). 

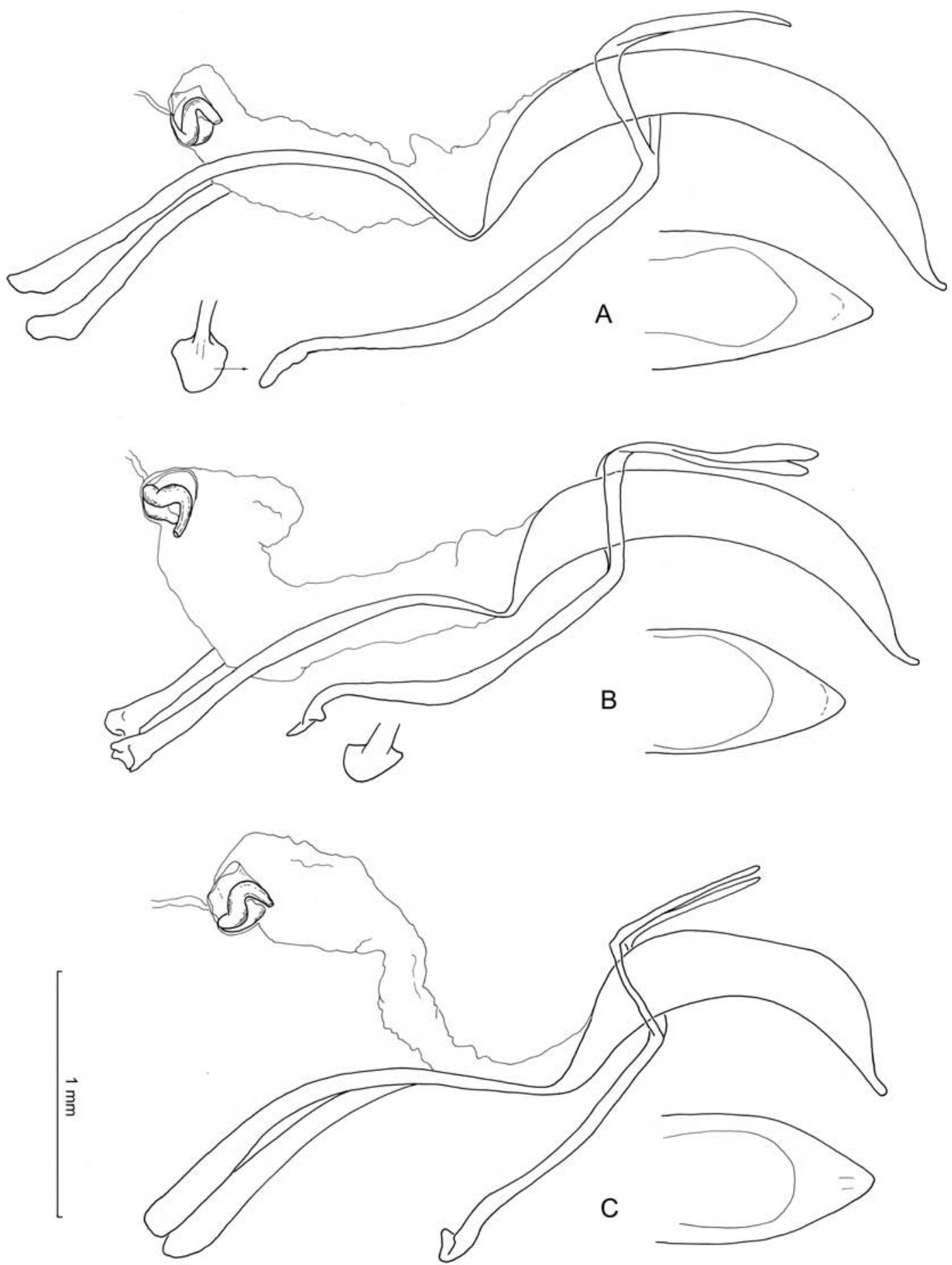

Fig. 8.- Edeago y detalle del ápice del lóbulo medio: Drouetius borgesi borgesi n. sp., de Terceira (A), Drouetius borgesi centralis n. ssp., de San Jorge (B) y Drouetius borgesi sanctimichaelis n. ssp., de San Miguel (C).

Fig. 8.- Aedeagus and detail of median lobe apex: Drouetius borgesi borgesi n. sp., from Terceira (A), Drouetius borgesi centralis n. ssp., from San Jorge (B) and Drouetius borgesi sanctimichaelis n. ssp., from San Miguel (C). 


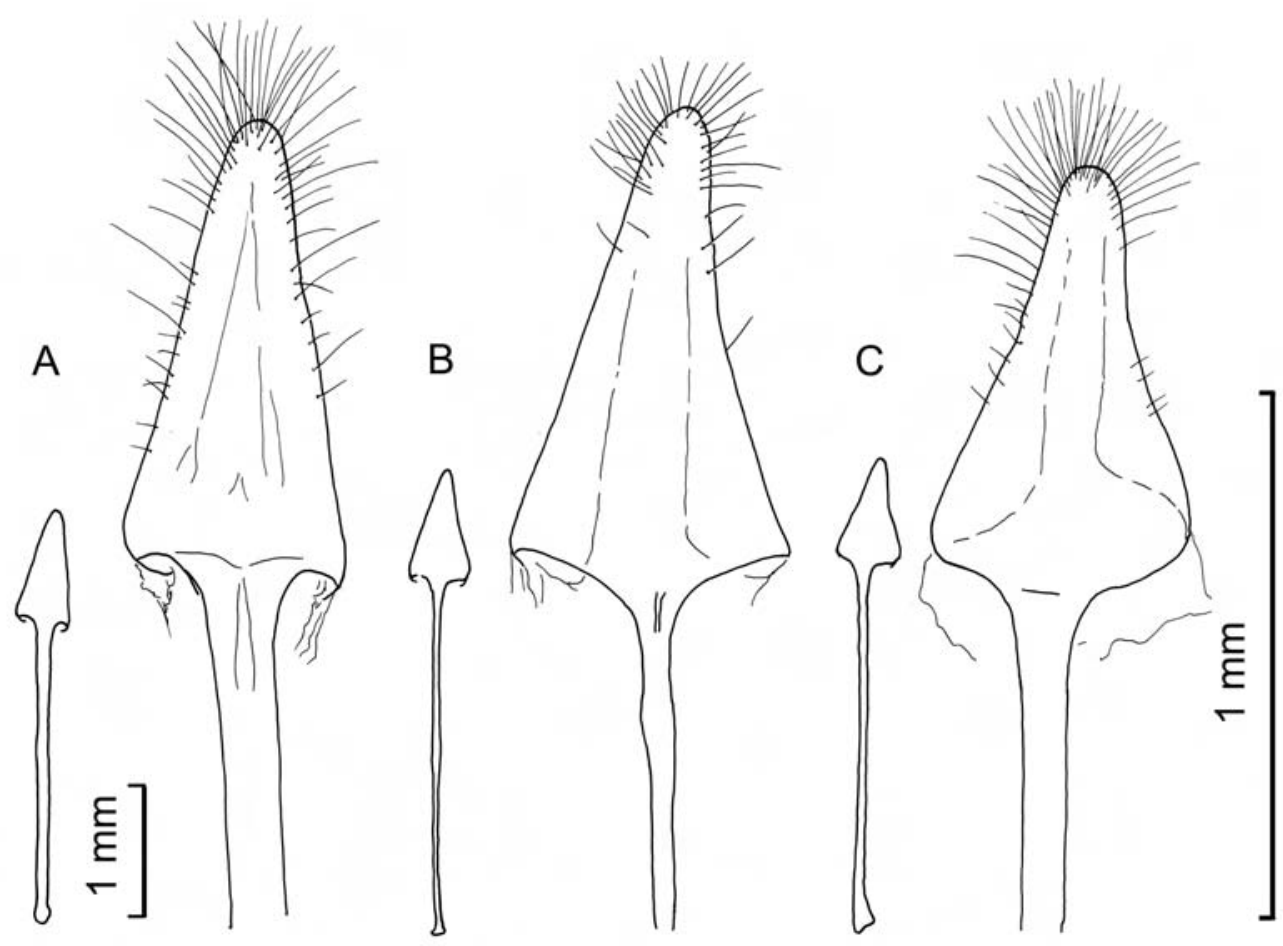

Fig. 9.- Esternito VIII femenino: Drouetius azoricus azoricus, de Graciosa (A), Drouetius borgesi centralis n.ssp., de San Jorge (B) y Drouetius oceanicus n.sp., de Terceira (C).

Fig. 9.- Female sternite VIII: Drouetius azoricus azoricus, from Graciosa (A), Drouetius borgesi centralis n.ssp., from San Jorge (B) and Drouetius oceanicus n.sp., from Terceira (C).

mómeros III-VI obcónicos y cortos; clava ovalada en punta, bastante gruesa, algo comprimida, igual o ligeramente mayor que los tres desmómeros anteriores juntos.

Pronoto poco más ancho que largo; con ligera depresión prebasal; lados poco curvados, más estrechos por delante; máxima anchura hacia la mitad; sin reborde basal; ángulos basales subrectos, brevemente romos (hembras ocasionalmente con reborde lateral sobresaliente); reborde anterior en banda amplia y lisa. Tegumento con punteado profundo sobre fondo liso; puntos separados un diámetro, algo más densos y menores en la base; línea media desarrollada; pubescencia diminuta y tumbada en la franja media, desarrollada y más larga hacia los flancos; las escamitas setiformes erguidas, sobresaliendo notoriamente del perfil lateral del pronoto (aspecto hirsuto).

Escudete breve, amplio, liso, a lo sumo con dos puntos.
Élitros oblongos, convexos; base tan ancha como la del pronoto; hombros desvanecidos o apenas insinuados; lados poco arqueados en el tramo medio (máxima anchura); estrías apenas impresas, señaladas por puntos mayores; tegumento ruguloso-punteado (microescultura de grandes celdas poligonales irregulares bien impresas, con punto foveiforme al centro); revestimiento abierto de escamitas piliformes inclinadas (120-140 $\mu \mathrm{m})$, mezclada con otras más finas, que dominan en el disco; algunas teselas (agrupación de escamitas más anchas y claras) en la mitad posterior. Sutura elitral ocasionalmente algo levantada en el ápice.

Patas robustas, punteadas (excepto meso y metafémures en su cara interna); tibias comprimidas lateralmente, carinadas en el canto externo, provistas de mucrón; protibias algo escotadas por dentro, brevemente curvadas apicalmente (más que en $D$. oceanicus), ángulo apical externo romo, el 

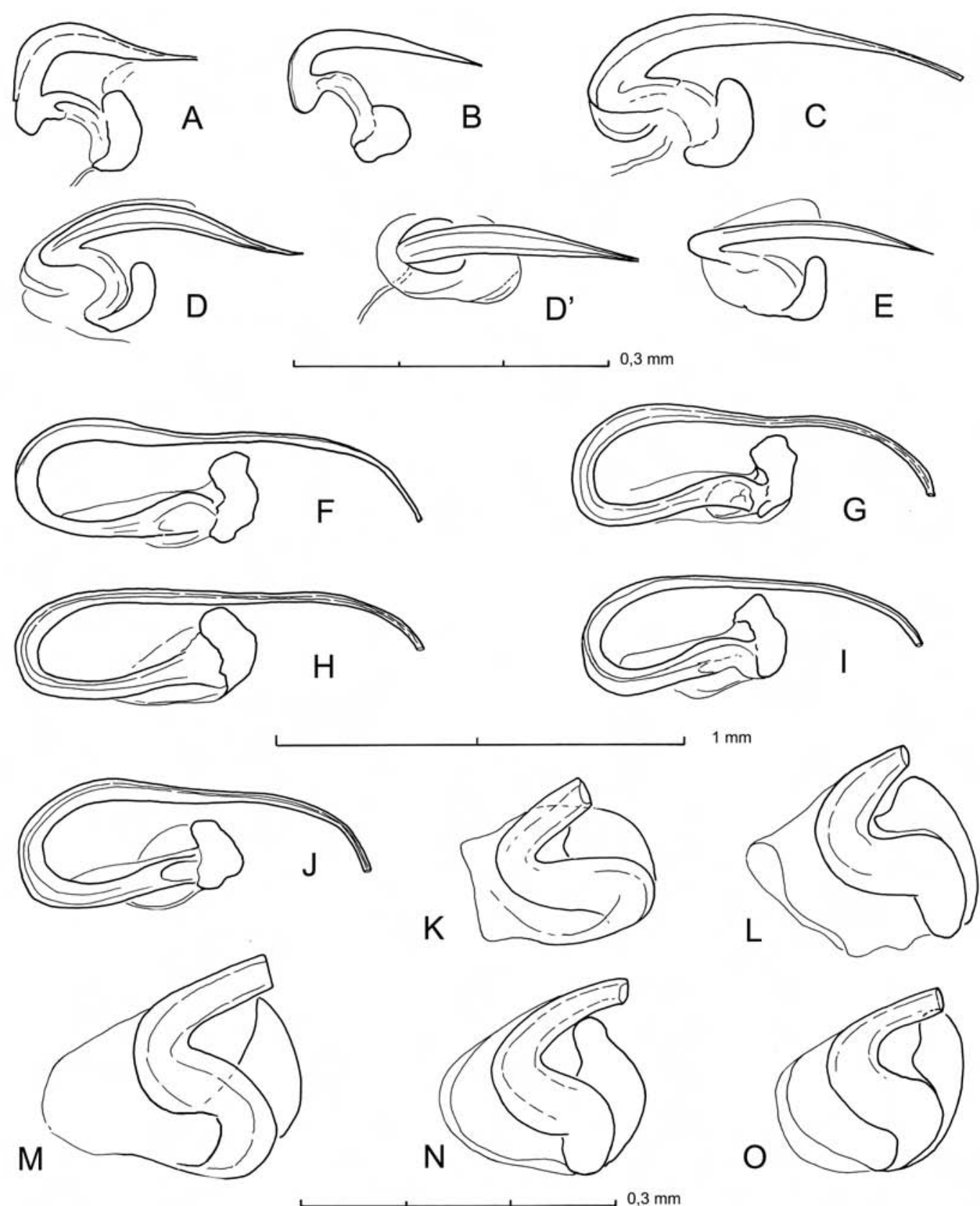

Fig. 10.- Transponedor del saco interno del edeago: Drouetius azoricus azoricus, de Faial (A), Drouetius azoricus parallelirostris n. ssp., de Terceira (B), Drouetius azoricus separandus n. ssp., de San Miguel (C), Drouetius azoricus nitens n. ssp., de Flores (D-D') y de Corvo (E), Drouetius oceanicus n. sp., de Terceira (F), Drouetius oceanicus tristis n. ssp., de Graciosa (G), de Faial $(\mathrm{H})$, de San Miguel (I) y de San Jorge (J), Drouetius borgesi n. sp., de Terceria (K), Drouetius borgesi sanctimichaelis n. ssp., de San Miguel (L), Drouetius borgesi centralis n.ssp., de Graciosa (M), de San Jorge (N) y de Pico (O).

Fig. 10. - Internal sac transfer apparatus of aedeagus: Drouetius azoricus azoricus, from Faial (A), Drouetius azoricus parallelirostris n. ssp., fromTerceira (B), Drouetius azoricus separandus n. ssp., from San Miguel (C), Drouetius azoricus nitens n. ssp., from Flores (D-D'), idem, from Corvo (E), Drouetius oceanicus n. sp., from Terceira (F), Drouetius oceanicus tristis n. ssp., from Graciosa (G), idem, from Faial (H), idem from San Miguel (I), idem, from San Jorge (J), Drouetius borgesi n. sp., from Terceria (K), Drouetius borgesi sanctimichaelis n. ssp., from San Miguel (L). Drouetius borgesi centralis n.ssp., from Graciosa (M), idem, from San Jorge $(\mathrm{N})$, idem, from Pico $(\mathrm{O})$. 
interno agudo (mucrón fuerte); pilosidad de los fémures en su cara ventral larga y erguida; pilosidad de las tibias progresivamente densa hacia el ápice. Tarsos amplios, triangulares, punteados.

Cara ventral: Acetábulo procoxal bien separado del margen anterior del prosterno. Esternitos abdominales con pilosidad larga, fina, inclinada y abierta; puntos más superficiales que en el dorso.

Edeago (Fig. 6A): Lóbulo medio uniformemente arqueado, nada aguzado apicalmente (visto de perfil), punta de planta ampliamente ojival; temones más largos que el lóbulo medio, ángulo de unión muy abierto (obtuso); saco interno largo, rebasando hacia atrás los temones (en reposo), con pieza laminar preapical muy poco diferenciada; transponedor muy pequeño $(<0,2 \mathrm{x}$ longitud temones), en forma de manivela con punta afilada, breve y abruptamente curvada en la base, su cuerpo basilar alejado y conectado por tejido menos esclerotizado (Fig. 10A).

Hembras: Tallas 9,0-9,1 mm. Más robustas y anchas. Escapo algo menor. Pronoto con lados más arqueados, ligeramente sinuosos en mitad anterior; línea media menos desarrollada; base ocasionalmente con reborde lateral sobresaliente. Élitros menos convexos, con la base más ancha que la del pronoto (hombros subrectos, muy marcados); máxima anchura por detrás de la mitad, algo más acuminados hacia el ápice; teselas más frecuentes, formadas por grupitos de una docena de escamitas más claras.

Pro y mesomucrón menos desarrollados, ausente en metatibias. Espermateca de cuerpo bulboso, cola muy cerrada sobre éste; lóbulo glandular corto y muy ancho (Fig. 11A).

OBSERVACIONES: Uyttenboogaart (1940, 1947) comenta varias imprecisiones de la descripción original de Laparocerus azoricus Drouet, 1859 tras haber estudiado 74 ejemplares procedentes de las Azores (Corvo, Flores, Faial, San Jorge, San Miguel y Terceira), y afirma que la variación observada en tamaño y escultura era igual en todas las islas, sin percatarse que tenía ante sí al menos dos especies distintas. A pesar de su gran parecido general, que es cierto, Drouetius azoricus se separa fácilmente de $D$. oceanicus por la presencia de escamitas sobresalientes del perfil lateral del pronoto, en vista dorsal. En D. oceanicus las escamitas están aplastadas contra el tegumento y no sobresalen. Además, en caso de que los ejemplares hayan perdido el revestimiento, una inspección del edeago despeja toda duda (Fig. 10). El transponedor del saco interno tiene forma de manivela y es de tama- ño minúsculo en $D$. azoricus -no llega a un quinto de la longitud de los temones- mientras que en $D$. oceanicus es enorme, tan o más largo que la mitad de los temones, y con forma de flagelo recurvado en su base, como un anzuelo. Las hembras de $D$. azoricus son fácilmente reconocibles por carecer de setas erguidas sobre los intervalos impares, y por sus hombros más rectos.

La especie está presente en todo el archipiélago salvo en Pico y Santa María. La impresión obtenida a partir del material reunido es que existe diferenciación morfológica según las islas, aunque en el caso de San Jorge y Graciosa el número de ejemplares es insuficiente para caracterizarlas con rigor, por lo que estas poblaciones insulares se asimilan de momento a la subespecie nominotípica. Las dos hembras de San Jorge presentan los ojos algo más pequeños y romos, y los lados del pronoto más curvados en la base. El macho y dos hembras de Graciosa se diferencian por la pubescencia algo más desarrollada y larga, y los ojos aún menos sobresalientes.

Las poblaciones de Terceira y de San Miguel se describen a continuación como subespecies, lo mismo que las del conjunto de Corvo y Flores, las islas más occidentales y alejadas. Esta última población, D. azoricus nitens n. ssp., es la más diferenciada, destacando por su brillo, tamaño menor, tegumentos menos esculpidos y forma más redondeada del pronoto y élitros. Tales diferencias pueden justificar un estatus de especie, pero se ha seguido el criterio de mantener reunidas como especie a todas las poblaciones insulares que comparten el mismo tipo de transponedor en el edeago.

Además, la distancia genética obtenida (Tabla 2) entre $D$. azoricus nitens y $D$. azoricus azoricus es mucho menor $(2,9 \%)$ que con $D$. azoricus parallelirostris $(4,5 \%)$, o la que existe entre esta última y D. azoricus azoricus $(4,6 \%)$.

\section{Drouetius azoricus nitens ssp. nov.}

(Figs. 4H, 5B, 6B y 10D-E y 13)

LOCALIDAD TÍPICA: Isla de Flores.

Laparocerus azoricus, in Uyttenboogaart 1940 p. 268 [pars]. Laparocerus azoricus, in Uyttenboogaart 1947 p. 8 [pars].

Laparocerus (Drouetius) azoricus, in Méquignon 1942 p. 52 [pars].

Laparocerus azoricus, in Serrano 1982 p. 90 [pars]. Laparocerus azoricus, in Borges 1992 p. 35 [pars]. Laparocerus azoricus, in Borges 2005 p. 201 [pars].

Material eXaminado. Flores: Sin localidad precisa. $10^{7}$ holotipo, sin fecha, leg. Walker (NHM, Coll. General BM 1927409).- Paratipos: mismos datos, 1 오. Sin localidad precisa $10^{\circ}$ 
8-1939, leg. K. Byström (NRS, Coll. General).- Vales. $10^{7}$ inmaturo 6-1938, leg. R. Storå. (ZMUH, Coll. Frey \& Storå).Santa Cruz.1 ㅇ inmatura 6-1938, leg. R. Storå. (ZMUH, Coll. Frey \& Storå)

No paratipos: Corvo: Ribeira das Rocinhas, 163 m, $10^{7}$ [deforme] 1 우 28-7-2007, leg. F. Pereira (AMC).- Sin localidad precisa: $2 \sigma^{\top} \sigma^{\top}$ 8-1939, leg. K. Byström (NRS, Coll. General).- [Fondo de la Caldera, fide Méquignon, 1942] 11 exx [non Guerne] + 4 exx. [8-]1888, leg. J. de Guerne (MNHN, Coll. Ch. Alluaud).

DiAgNOSIS DIFERENCIAL. Talla menor $\left(0^{\pi} \sigma^{7} 6,2-\right.$ $7,5 \mathrm{~mm}$, 우 우 7,4-8,5 mm) que la subespecie nominotípica, de aspecto menos oblongo y más brillante. Pterigios del rostro subparalelos, nada o apenas salientes; ojos menos cónicos y prominentes (convexidad $40 \%$ ); escapo más grácil; desmómeros VVII algo más globosos. Pronoto con tegumento brillante, punteado más débil, abierto y superficial (puntos separados más de dos diámetros) microrreticulación isodiamétrica menuda bien visible en los intervalos; lados notablemente más redondeados (Fig. 5B), base poco cuadrangular, ángulos posteriores más obtusos ( 우 우 bastante romos); escamitas erguidas en los flancos menos aparentes, conspicuas solo en la mitad basal. Élitros más ovales (máxima anchura al centro), sin hombros en $\mathrm{O}^{7} \mathrm{O}^{7}$, esbozados en $ᄋ$ 우, muy obtusos; tegumentos muy brillantes (ruguloso-alutáceos en 우 우); microescultura superficial, poco impresa escamitas normalmente adpresas, cortas y anchas $(<100 \mu \mathrm{m})$, en el tramo medio muy reducidas; sutura no levantada en el ápice. Tibias más escotadas interiormente, no carinadas exteriormente; pilosidad ventral de los fémures algo menos desarrollada. Edeago muy ancho; lóbulo medio brevísimamente levantado en la punta, apertura apical más avanzada (Fig. 6B); temones cortos, igual o apenas más largos que el cuerpo principal del lóbulo medio; saco interno hacia atrás mucho más corto que los temones; transponedor menos arqueado, con valvas mayores y pieza basal más delicada (Figs. 10D y E).

ETIMOLOGíA: El nombre hace alusión al brillo de los tegumentos.

\section{Drouetius azoricus parallelirostris ssp. nov.} (Figs. 6C, 10B y 11B)

LOCALIDAD TÍPICA: Monte Brasil (Angra do Heroismo) en Terceira.

Material examinado. Terceira: Angra do Heroísmo, Monte Brasil 150 m, $10^{7}$ holotipo 15-6-2008, sobre Salpichroa origanifolia (Solanaceae) leg. A. Machado (TFMC $\mathrm{n}^{\circ} \mathrm{CO}-15803$ ). Paratipos: mismos datos de colecta 19 우 우 (AMC), $10^{\pi} 1$ 우 (DCA), $10^{\top}(\mathrm{GO}), 10^{\top} 1$ ㅇ (ZMUH).
Diagnosis DifERENCIAL. Tallas: $\sigma^{\pi} \sigma^{\pi} 7,0-8,2$ $\mathrm{mm}$, 우 우 7,9-9,8 $\mathrm{mm}$. Aspecto general más oblongo y diferencias entre sexos menos acusada. Rostro de márgenes paralelos; pterigios nada salientes. Ojos $\sigma^{7} \sigma^{7}$ menos cónicos, menos asimétricos y menos prominentes. Abultamiento apical del escapo peor delimitado. Pronoto de lados más curvos en la mitad posterior (máxima anchura), y algo más sinuosos en la mitad anterior; reborde basal lateral sobresaliente en el ángulo (puntita breve) en ambos sexos; línea media menos desarrollada y más fina; punteado profundo, casi coalescente, menor y más apretado en la base. Élitros con máxima anchura en el centro, en $ᄋ$ 우 algo más anchos (y menos arqueados), pero no tanto como en la ssp. azoricus; pilosidad elitral más uniformemente desarrollada, fina y larga, de color dorado (formando bastantes teselas de escamitas piliformes claras, algo más anchas). Tibias menos comprimidas lateralmente; apenas carinadas en margen externo; protibias $0^{7} \sigma^{7}$ más escotadas internamente. Declive apical del lóbulo medio del edeago más pronunciado (visto lateralmente); lámina esclerotizada preapical del saco interno bien diferenciada (Fig. 6C).

ETimología: El epíteto subespecífico hace alusión a la conformación del rostro, cuyos márgenes discurren en paralelo.

\section{Drouetius azoricus separandus ssp. nov.}

(Fig. 6D)

LOCALIDAD TíPICA: Isla de San Miguel.

Laparocerus azoricus, in Crotch 1867 p. 388 [pars]

Laparocerus (Drouetius) azoricus, in Méquignon 1942 p. 52.[pars]

Laparocerus azoricus, in Borges 1992 p. 35 [pars].

Laparocerus azoricus, in Borges 2005 p. 201 [pars].

Material eXaminado. San Miguel: Sin localidad precisa, $10^{\pi}$ holotipo, 1888, leg.J. de Guerne (MNHN, Coll. Ch. Alluaud); 1 ㅇ paratipo, [Agosto 1887 fide Méquignon 1942] leg. D. Nodier (MNHN, Coll. Roudier).

Existe un ejemplar hembra en la Coll. Heyden [DEI] con una etiqueta grande "Azores, San Miguel" que no pertenece a esta subespecie sino a la nominotípica. Es posible que esta etiqueta refleje la isla desde la que se envió el insecto, pero no donde se recolectó. Este tipo de error era frecuente en siglo XIX

DiAgNosis DIFERENCIAL. Tallas: $0^{7} \sigma^{\pi} 7,5 \mathrm{~mm}$, 우 우 8,5-9,9 $\mathrm{mm}$. Márgenes ventrales del rostro subparalelos, pterigios algo salientes (menos que en ssp. azoricus). Pronoto de lados más curvados, más estrechado por delante; base sin reborde lateral 


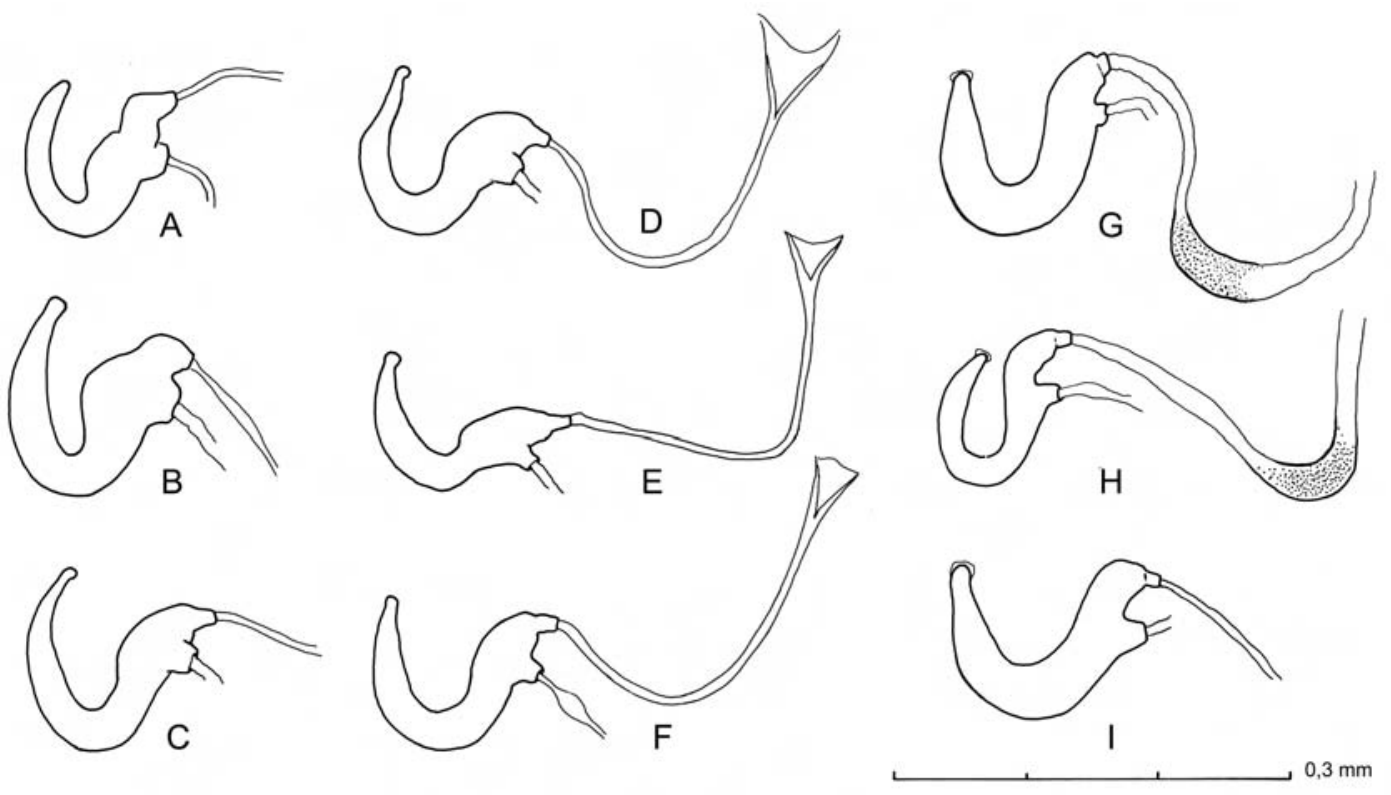

Fig. 11.- Espermateca: Drouetius azoricus azoricus, de San Jorge (A), Drouetius azoricus parallelirostris n. ssp., de Terceira (B), Drouetius borgesi n. sp., de Pico Galhardo, Terceira (C) y de Pinheiro Rachado, Terceira (D), Drouetius borgesi centralis $\mathbf{n}$. ssp., de Pico (E) y de San Jorge (F), Drouetius oceanicus n. sp., de Terceira (G) y Drouetius oceanicus tristis n. ssp., de Graciosa (H) y de Faial (I).

Fig. 11.- Spermatheca: Drouetius azoricus azoricus, from San Jorge (A), Drouetius azoricus parallelirostris n. ssp., idem, from Terceira (B), Drouetius borgesi n. sp., from Pico Galhardo, Terceira (C), ídem from Pinheiro Rachado, Terceira (D), Drouetius borgesi centralis n. ssp., from Pico (E), ídem, from San Jorge (F), Drouetius oceanicus n. sp., from Terceira (G) and Drouetius oceanicus tristis n. ssp., from Graciosa (H), ídem from Faial (I).

sobresaliente. Élitros oval-alargados y convexos $\left(\sigma^{\top} \sigma^{\top}\right)$, anchos, bastante deprimidos y con base más cuadrangular ( $ᄋ$ ᄋ ), ángulo humeral subrecto, muy marcado; punteado más débil, pilosidad más corta, los pelitos se solapan a lo sumo en 1/3 (en ssp. azoricus 1/2-2/3); sutura levantada en el ápice (우 우). Metatibias más cilíndricas, poco comprimidas lateralmente. Lóbulo medio del edeago subrecto en su tramo medio, visto de perfil; el saco interno, hacia atrás, no más largo que los temones (Fig. 6D).

ETIMOLOGía: El epíteto subespecífico deriva del latín separatus, separado, apartado, distinto.

\section{Drouetius oceanicus n. sp.}

(Figs. 4G, 5C, 7A, 9C, 10F, 11G y 14)

LOCALIDAD TíPICA: Praia da Vitoria en Terceira.

Laparocerus azoricus, in Uyttenboogaart 1940 p. 268.[pars] Laparocerus azoricus, in Uyttenboogaart 1947 p. 8. [pars] Laparocerus (Drouetius) azoricus, in Roudier 1965 p. 39 [pars?].
Laparocerus azoricus, in Borges 1992 p. 35 [pars].

Laparocerus azoricus, in Borges 2005 p. 201 [pars].

Material examinado: Terceira: Praia da Vitoria. $10^{7}$ holotipo, 8/10-6-1938, leg. Richard Frey (ZMUH, Coll. Frey \& Storå). Paratipos: mismos datos de colecta, 31 exx (ZMUH, Coll. Frey \& Storå), $10^{\nearrow} 1$ ㅇ (AMC).

En la Colección Godman (NHM) existe una serie de 5 우 우 (¡no paratipos!) con etiqueta "loc. a 8" (registro BM 1871-4) cuyo significado no se ha podido desvelar. En su periplo por las Azores, Godman (1870) colectó en Flores, Corvo, Faial y San Miguel, mientras que en Terceira estuvo solo un día (22-41865). Sin embargo, su asistente en las colectas, Mr. Brewer, se quedó un mes más para visitar Santa María y luego tuvo que volver obligadamente a Terceira para coger el barco de regreso. No se puede, pues, descartar que estos ejemplares no hayan sido colectados en Terceira.

DESCRIPCIÓN. Machos (Terceira): Talla 7,0-8,2 $\mathrm{mm}$. Bastante parecido a $D$. azoricus. Insecto oblongo-alargado; tegumento subnítido de color píceo, fuertemente punteado (en antenas y tibias, algo más superficialmente). Pronoto y élitros con revestimiento llamativo de escamitas lanceoladas casi 
adpresas de color flavo (visos cobrizos o glaucos) en los márgenes, piliforme, menor y rala en el resto.

Cabeza más robusta; rostro, cuadrangular (algo más ancho que largo), márgenes dorsales algo convergentes hacia delante, no estrangulado, márgenes ventrales subparalelos; pterigios breves, apenas salientes; tegumento punteado más superficialmente, poco rugoso; línea media fina, prolongada en la frente.

Ojos cónicos, moruloides, salientes (convexidad $42 \%$ ), su cénit desplazado hacia atrás, emplazados a media altura en la cabeza.

Antenas robustas; escapo capitado, punteado superficial; funículo más largo que la longitud del pronoto; desmómeros III-VI obcónicos; clava gruesa, comprimida, algo más larga que los tres desmómeros anteriores juntos.

Pronoto poco más ancho que largo $(1,1 \mathrm{x})$, algo estrechado por delante; lados poco arqueados, máxima anchura hacia o pasada la mitad; base en el centro algo sinuosa, sin reborde; ángulos basales subrectos, con reborde lateral sobresaliente (punta breve); reborde anterior en banda más estrecha y lisa, con algún punto. Tegumentos lisos, brillantes, con puntos precisos (menores y menos profundos que en D. azoricus azoricus), separados 2-3 diámetros entre sí, algo más densos y menores en la base; línea media poco desarrollada o ausente. Escamitas lanceoladas flavas, largas, llamativas, muy tumbadas, solapándose en los flancos, sin sobresalir sobre el perfil del pronoto; el tramo medio despejado, con pelitos pequeños dorados, levantados e inconspicuos.

Escudete breve, amplio, liso, sin puntos.

Élitros oblongos (1,5x más anchos que el pronoto); máxima anchura sobre la mitad, lados poco arqueados; estrías apenas impresas, marcadas por puntos mayores; los intervalos a veces algo convexos y marcados; tegumento ruguloso-punteado (microescultura de grandes celdas poligonales irregulares bien impresas, con punto foveiforme al centro); revestimiento abierto de pelitos finos menores y escamitas flavas lanceoladas mayores, tumbadas (no adpresas), formando dibujo en teselas, algo levantadas en los hombros y ápice. Sutura elitral brevemente levantada en el ápice.

Patas moderadamente robustas, punteadas (excepto meso y metafémures en su cara interna); tibias comprimidas lateralmente, débilmente carinadas en el canto externo, provistas de mucrón; protibias ligeramente curvadas apicalmente, ángulo apical externo romo, el interno agudo (mucrón fuerte); pilosidad de los fémures en su cara ventral larga y erguida solo en la base; pilosidad de las tibias progresivamente densa hacia el ápice. Tarsos amplios, triangulares, punteados.
Cara ventral: Acetábulo procoxal bien separado del margen anterior del prosterno.

Procoxas subtangentes o algo separadas. Esternitos abdominales con pilosidad abierta, fina, larga e inclinada al centro, lanceolada, tumbada y más ancha en los lados; puntos más superficiales que en el dorso.

Edeago (Fig. 7A): Lóbulo medio más arqueado apicalmente (visto de perfil), punta de planta ancha, subtriangular, con la apertura apical muy retrasada; temones no mucho más largos que el cuerpo principal, formando ángulo recto o agudo en su unión, bastante curvados en la base; saco interno corto, hacia atrás no más largo que los temones; transponedor enorme ( $>0,3 \mathrm{x}$ longitud temones), en forma de flagelo largo recurvado sobre su mitad basal, pieza basilar unida al flagelo, valvas estrechas (Fig. 10F).

Hembras: Talla 8,1-9,4 mm. Más robustas y anchas. Base del pronoto más cuadrangular. Élitros algo abombados y más acuminados en la mitad posterior; hombros breves, redondeados; intervalos impares provistos de una hilera de setas levantadas.

Mucrón de las pro y mesotibias muy pequeño. Espermateca (Fig. 11G) tubular, cuerpo y cola sin solución de continuidad; lóbulo glandular corto, estrecho.

ETIMOLOGÍA. El nombre hace alusión a la condición oceánica de las islas Azores, donde vive el insecto.

ObServaciones. Drouetius oceanicus n. sp. se parece mucho a $D$. azoricus, especie con la que se ha venido confundiendo, a pesar de ser fácil de separar por la ausencia de escamas levantadas en los laterales del pronoto, o por la presencia de hileras de setas erguidas en los intervalos impares de los élitros femeninos. La subespecie nominotípica de Terceira es la más llamativa por su revestimiento de escamas flavas en los flancos, mientras que los ejemplares de Corvo, Faial, San Jorge, Graciosa y San Miguel son menos contrastados y de aspecto más parecido a $D$. azoricus. Las diferencias entre los ejemplares de estas cinco islas son de carácter menor $\mathrm{y}$, a falta de más material para poder evaluar su alcance, se reúnen a continuación en una única subespecie.

\section{Drouetius oceanicus tristis ssp. nov.}

(Figs. 3A-D, 4C-F, 7B-C, 10G-J y 11H-I)

LOCALIDAD TíPICA: Pico Timão en Graciosa.

Laparocerus azoricus, in Uyttenboogaart 1940 p. 268 [pars]. Laparocerus azoricus, in Uyttenboogaart 1947 p. 8 [pars]. 
Fig. 12.- Lectotipo y paralectotipo de Drouetius azoricus (Drouet, 1859).

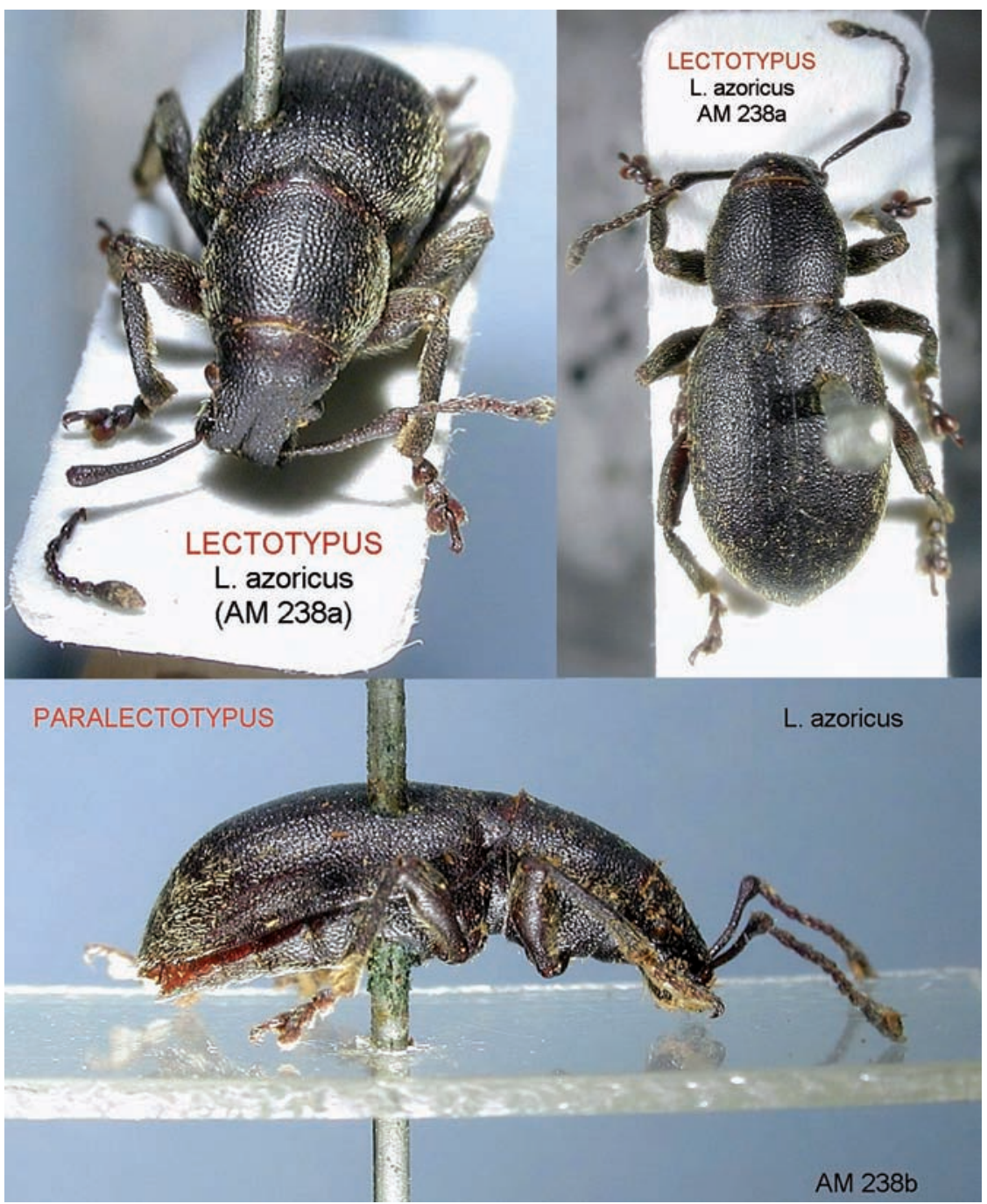

Fig. 12.- Lectotype and paralectotype of Drouetius azoricus (Drouet, 1859).

Laparocerus (Drouetius) azoricus, in Roudier 1965 p. 39 [pars?]. Laparocerus azoricus, in Borges \& Serrano 1989 p. 19 [pars].

Material examinado. Graciosa: Pico Timão. $10^{\top}$ holotipo 20-8-1987, leg. P. Borges (TFMC CO-15807). Paratipos: mismos datos de colecta, $10^{7}$ (AMC), 1 ㅇ (DCA).

No paratipos: Corvo: Sin localidad precisa, $20^{7} \sigma^{7} 1$ ㅇ 8-1939 leg. K. Byström (NRS). Faial: Pasteleira. 2 exx 20-6-1946, leg. M.I. Russel (MNHN, Coll. Roudier); 5 exx. 26-6-1956, leg. M. Ruspoli, "sous pierres" (GO).- Porto Pim 3 exx 5-6-1956 leg. M. Ruspoli (2 GO, 1 AMC), 3 exx 12-6-1956 leg. M. Ruspoli (1 GO, 1 AMC, 1 MNHN).- Sin localidad precisa, 4 exx. leg. L. von Heyden (DEI, Coll. Heyden). San Jorge: Ilhéu do Topo. 2 exx. 26-6-1938, leg. R. Frey. (ZMUH, Coll. Frey \& Stora).- Sin localidad precisa, 2 exx. 8-1897, leg. Richard (MNHN, Coll. Ch. Alluaud). San Miguel: Ponta Delgada. 2 exx sin fecha, leg. L. von Heyden (DEI, Coll. Heyden).- Loc. 20496, 2 exx. sin fecha, leg. Tarnier (NHM, Coll. Fry 19805-100).- Sin localidad precisa, $10^{7} 1$ ㅇ leg. Tarnier (NRS, Coll. Chevrolat), [San Miguel, fide S. Shute] 2 exx sin fecha, leg. Lethierry et al. (NHM, ex Coll. Sharp 1948-336).
Hay 7 ejemplares entre el material reunido que no lleva indicación sobre la isla de procedencia. (leg Godman, J. de Guerne?, Grandl y Dohrn).

DiAgnosis DIFERENCIAL. Talla: $\sigma^{7} \sigma^{\pi} \quad 6,9-8,5$ $\mathrm{mm}$, 우 우 8,9-10,4 mm. Pronoto algo más profundamente punteado que la subespecie nominotípica, y pilosidad muy corta y nada aparente. Élitros $\sigma^{7} \sigma^{\prime \prime}$ con pilosidad rala y corta, las escamitas flavas mucho más cortas, en las 우 우 algo mayores y algo levantadas, sobre todo en los hombros, pero siempre menores y mucho menos llamativas que en la subespecie nominotípica; el número de teselas claras (4-6 escamitas) generalmente escaso. La curvatura de los lados del pronoto varía un poco según las islas. Los élitros de las $\sigma^{x} \sigma^{x}$ son algo más anchos y menos convexos. 

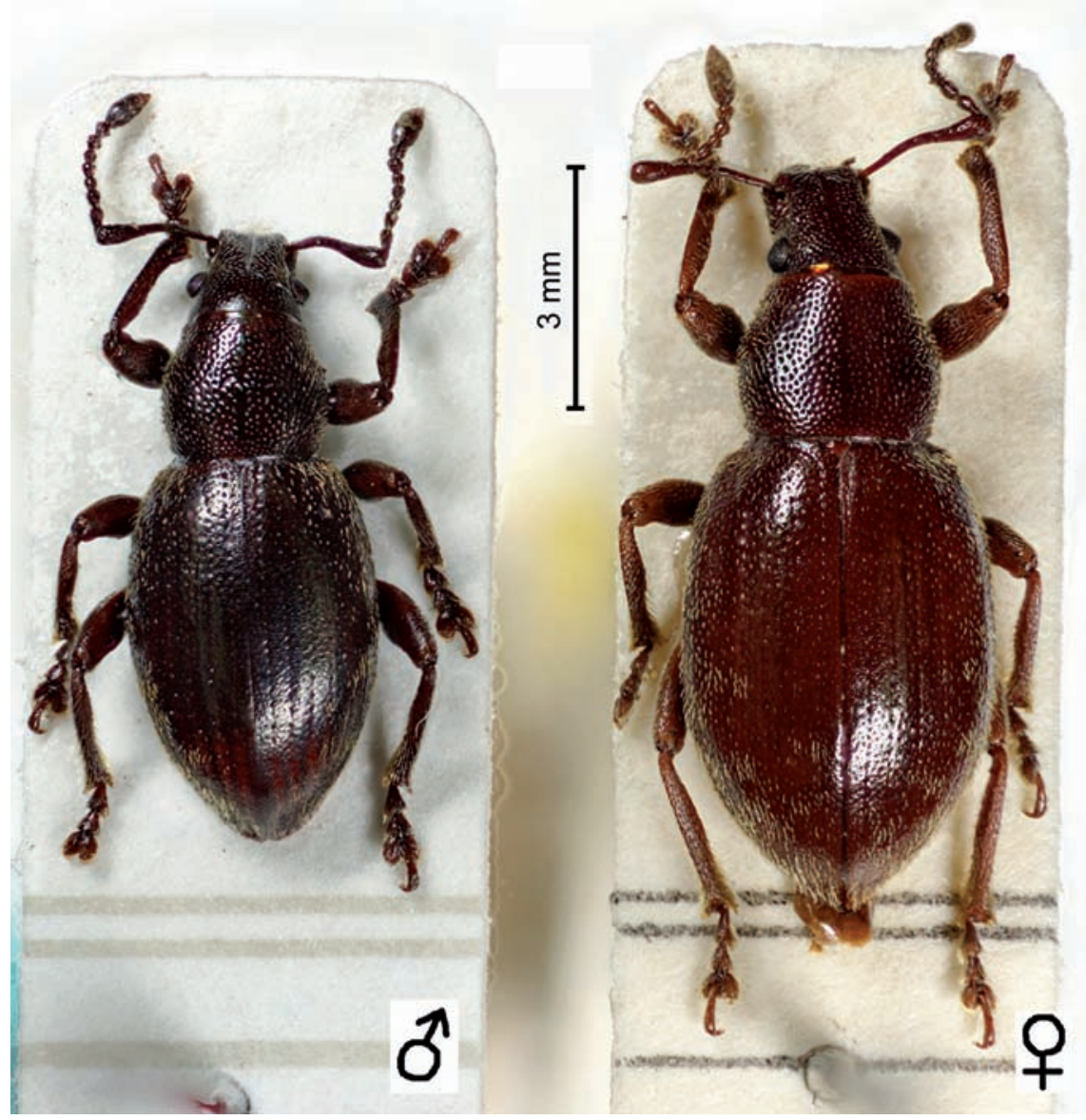

Fig. 13.- Holotipo $0^{7}$ y paratipo 우 de Drouetius azoricus nitens n. ssp.

Fig. 13.- Holotype $\sigma^{\pi}$ and paratype 우 of Drouetius azoricus nitens $\mathbf{n}$. ssp.

Etimología. El epíteto subespecífico hace alusión al aspecto menos llamativo (tristis $=$ de aspecto sobrio), en relación con la subespecie nominotípica.

\section{Drouetius borgesi n. sp.}

(Figs. 3A, F-G, 4A-B, 5D, 8A, 10K, 11C-D y 15)

LOCALIDAD TíPICA: Serra de Santa Bárbara en Terceira.

Laparocerus azoricus, in Borges 1999 p. 21.

Laparocerus azoricus, in Borges et al. 2000 p. 146 [pars]

Laparocerus azoricus, in Borges 2005 p. 201 [pars].

Laparocerus azoricus, in Borges et al. 2006 p. 186.

Laparocerus n. sp., in Machado et al. 2008 p. 417 [ADN].

Material examinado. Terceira: Serra de Santa Bárbara, Lomba, 750 m (N 38 44'20" W 27017'40") $10^{\prime \prime}$ holotipo 13-72004, leg. A. Machado (TFMC CO-15804). Paratipos: mismos datos, 26 exx, leg. A. Machado (AMC) Genebank EF583350 (COII) EF583418 (16sRNA).- Terra Brava 700 m (N 38 43'70" W $\left.27^{\circ} 12^{\prime} 40^{\prime \prime}\right) 3$ exx. 14-7-2004, leg. A. Machado (AMC); 2 exx. 1-6-2002, 1 ex. 1-7-2003, leg. BALA. (DCA).- Algar do Carvão. 690 m. (N 38 43'75” W 27¹2’450”) 6 exx. 14-7-2004, leg. A. Machado (AMC).- Lagoa do Negro, 1 ex. 1-7-1997, leg. proyecto BALA (DCA).- Pico Galhardo, 650 m. 2/4-7-2003, 18 exx (DCA) 3 exx (RB), 2 exx (GO), 1/3-9-2002 14 exx. (DCA) leg. proyecto BALA.- Ribeira Dos Gatos, 3 exx. 1-7-2003, leg. proyecto BALA (DCA).- Lomba Centro, 7 exx. 1-7-2003, leg. proyecto BALA (DCA).- Matela II, $667 \mathrm{~m} .1$ ex. 8-1999, leg. proyecto BALA (DCA).- Entre o Pico Pinheiro e o Pico Rachado. 14 exx. 1/ 4-7-2003, leg. proyecto BALA (DCA).

DESCRIPCIÓN. Machos: Talla: 8,5-9,5 mm. Insecto robusto fusiforme, de color pardo-pez algo rojizo. Tegumento fina y apretadamente punteado; pubescencia dorada abierta, fina, corta, tumbada hacia atrás y muy uniforme.

Cabeza cónica; rostro estrecho, algo más largo que ancho $(1,3 \mathrm{x})$, por arriba muy constreñido pasado el nivel de inserción de las antenas, por debajo ligeramente convergente hacia la base; pterigios breves, poco sobresalientes pero expuestos (base antenal visible); prorrostro sin puntear, sin quilla epistomal; metarrostro apenas acanalado, con surco medio fino (no penetra la frente); punteado coalescente.

Ojos grandes, ovalados, uniformemente convexos, apenas sobresalientes (convexidad 18\%), pró- 
Fig. 14.- Holotipo $\sigma^{x}$ y paratipo ○ de Drouetius oceanicus n. sp.

Fig. 14.- Holotype $\sigma^{\pi}$ and paratype $ᄋ$ of Drouetius oceanicus $\mathbf{n}$. sp.

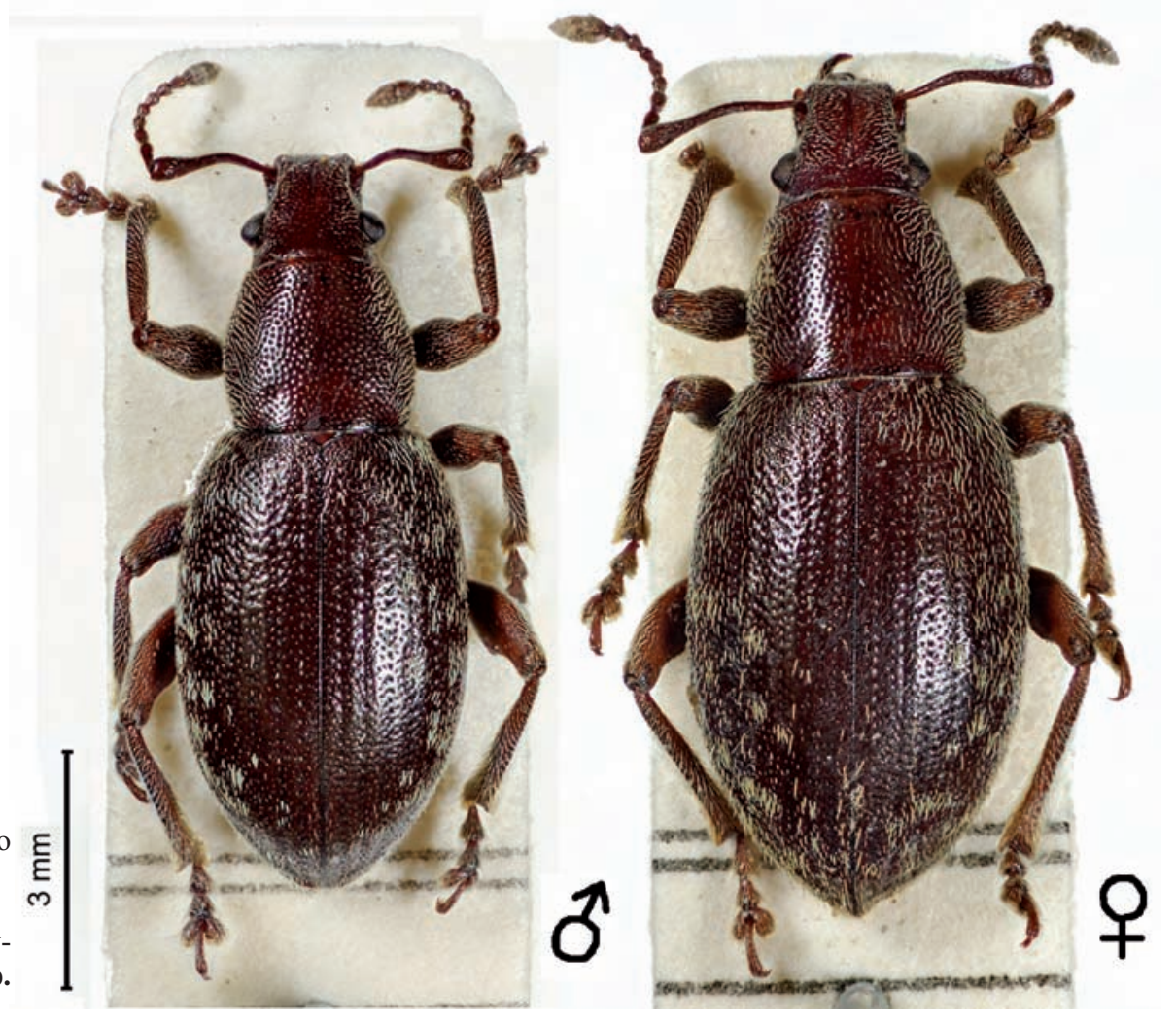

ximos al borde lateral de la frente, en posición más dorso-lateral que en las otras especies.

Antenas moderadamente punteadas; escapo menor que el funículo, ligeramente sinuoso en la base, brevemente capitado; desmómeros $1^{\circ}>2^{\circ}$; clava mucho más grácil que en las otras especies, tan larga como los cuatro desmómeros precedentes y $1,4 \mathrm{x}$ más ancha.

Pronoto grande y voluminoso $(0,45 \mathrm{x}$ longitud elitral), tan largo como ancho, de aspecto algo "calandriforme", mucho más estrechado por delante que por detrás; lados muy curvados (máxima anchura pasada la mitad), más rectilíneos y algo sinuosos en el tercio anterior; ángulos posteriores obtusos, base sin reborde en el tramo medio, muy débil lateralmente; reborde anterior liso y estrecho (no una banda ancha como en D. azoricus). Dorso poco convexo, superficie algo irregular, como con abolladuras leves; tegumento acribillado de puntos fuertes (intervalos < diámetro del punto); sin línea media. Pubescencia uniforme; las escamitas se aprecian en el perfil lateral, levantadas irregularmente (menos destacadas que en $D$. azoricus).

Escudete muy pequeño, liso; prescutum bastante punteado y con pilosidad. Élitros oval-alargados, de aspecto proporcionalmente corto (2,3x longitud del pronoto), 1,4x más anchos que el pronoto, máxima anchura hacia el primer cuarto; hombros desvanecidos; lados poco curvados en su tramo medio; sutura en el ápice no levantada. Estrías reconocibles entre el abigarrado punteado varioloso-granular, marcadas por puntos mayores; a veces los intervalos también algo convexos; microescultura de pequeñas celdas poligonales incisas, con punto central. Pubescencia dorada abierta, muy uniforme, delicada, inclinada hacia atrás, sin formar teselas o dibujo alguno (escamitas piliformes un poco más anchas hacia su base en flancos $\mathrm{y}$, particularmente, hombros).

Patas robustas, fémures con pilosidad normal en su cara ventral; tibias poco o nada canteadas en su arista externa; protibias nada o apenas escotadas por dentro (grosor uniforme), ligeramente arqueadas hacia delante, poco ensanchadas en el ápice, con mucrón grande, éste pequeño en mesotibias, ausente en metatibias.

Cara ventral. Procoxas muy adelantadas, tangentes al margen anterior del prosterno. Esternitos abdominales con punteado más abierto, pilosidad algo más larga que en los élitros. $1^{\mathrm{er}}$ y $2^{\circ}$ esternitos 


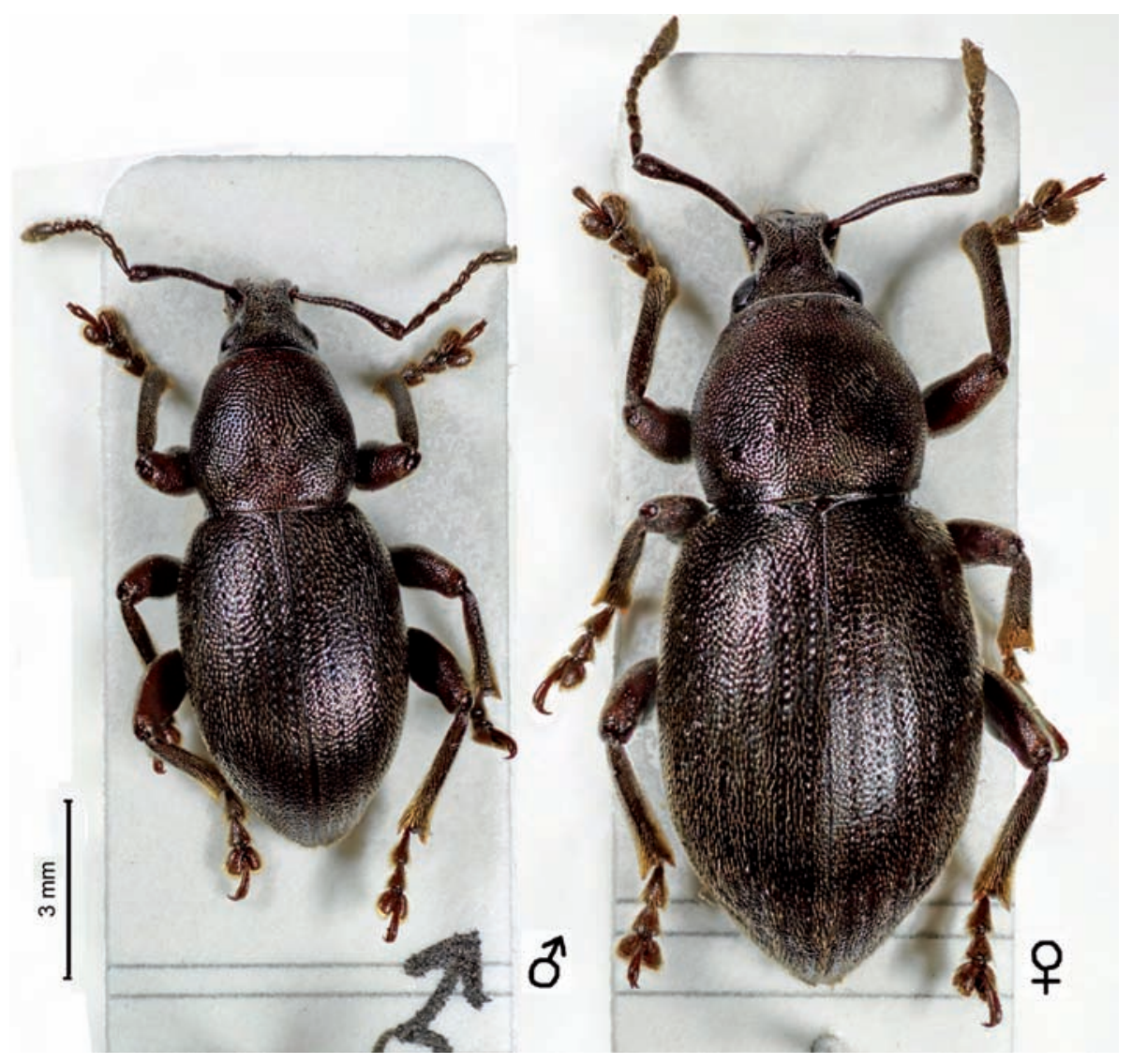

Fig. 15.- Holotipo ơ y paratipo 우 de Drouetius borgesi n. sp.

Fig. 15.- Holotype $\sigma^{\pi}$ and paratype $\$$ of Drouetius borgesi $\mathbf{n}$. $\mathbf{s p .}$ fundidos en el tercio medio, la sutura apenas arqueada.

Edeago (Fig. 8A). Temones más largos que el cuerpo principal del lóbulo medio, ambos arqueados y unidos en ángulo recto; ápice de planta triangular aguda, visto de perfil termina en punta progresivamente fina y levantada al final (con quilla incipiente), la apertura bastante retrasada; saco interno en reposo sin rebasar los temones; transponedor tubular grueso y pequeño, en forma de "S" con la punta truncada, emplazado en una amplia valva membranosa plegada sobre él (a modo de estuche), la pieza basal retraída junto a la base del tubo (Fig. 10K). Manubrio con extremo sagitado.

Hembras. Talla: 8,9-11,5 mm. Generalmente mayores, más anchas. Élitros de lados más curvados, máxima anchura algo por detrás de la mitad. Protibias con mucrón muy reducido, meso y metatibias inermes. Margen del último esternito abdominal en arco algo más cerrado que en el macho. Estilos de los hemisternitos estilizados (Fig. 4F); esternito VIII de pedúnculo fino, más fino que en las otras especies. Espermateca con el cuerpo diferenciado, lóbulo del ducto seminal, estrecho, alargado, el ducto bastante esclerosado y rígido, abierto en "V" rígida en su unión a la bolsa copulatriz (Figs. 11C-D).

Etimología. La especie está dedicada a su descubridor, el Dr. Paulo A.V. Borges, amigo y gran estudioso de la entomofauna azoreana y su ecología.

OBSERVACIONES. Esta especie se distingue fácilmente de Drouetius azoricus y D. oceanicus por su aspecto más fusiforme, con el pronoto voluminoso, más estrechado por delante, y densísimamente punteado. Además, el rostro está claramente estrangulado por detrás de la inserción de las antenas, y las procoxas son casi tangentes al borde anterior del prosterno, mientras que en las otras dos especies están bastante alejadas. El transponedor del saco interno del edeago es también muy peculiar, en forma de "S", y no cabe confusión alguna.

Drouetius borgesi no se conoce de Flores, Corvo ni Faial; sin embargo, se ha encontrado en la isla de Pico. Los ejemplares de San Miguel presentan diferencias claras en el revestimiento, forma de los élitros y del edeago (ssp. sanctimichaelis nov.) 
pero, al igual que en los casos anteriores, falta más material de las poblaciones de las islas centrales (Pico, Graciosa y San Jorge) para poder discernir si existen diferencias sustanciales entre ellas, por lo que se reúnen aquí bajo una misma subespecie (ssp. centralis nov.)

\section{Drouetius borgesi sanctimichaelis ssp. nov.} (Figs. 8C y 10L)

Localidad tíPICA: Pico da Vara en San Miguel.

Laparocerus azoricus, in Borges 2005 p. 201 [pars].

Material examinado. São Miguel: Pico da Vara, 450 m. $1 \sigma^{\pi}$ holotipo 1-7-2000, leg. P. Borges (TFMC CO-15806). Paratipos: Mismos datos $10^{\prime \prime}$ (AMC).- Ponta Delgada, 1 \& leg. L. von Heyden (DEI, Coll. Heyden).

No paratipos: San Miguel. 2 exx, sin más datos (NRS, Coll. General).

DiAgnosis DifERENCIAL: Talla: $\sigma^{7} \sigma^{7} 7,1-7,7 \mathrm{~mm}$, ㅇ $9,5 \mathrm{~mm}$. Igual que la subespecie tipononimal, pero pubescencia poco aparente, más reducida, más tumbada y más corta (los pelitos apenas alcanzan la base del siguiente) sobre todo en el disco elitral, y menos en los callos humerales y flancos. Ojos notoriamente más salientes (convexidad 34\%), el vértice desplazado hacia atrás, pero no cónicos. Rostro algo más corto y menos estrangulado dorsalmente; pterigios menos salientes; surco rostral prolongado en la frente casi o hasta el nivel posterior de los ojos $\left(\sigma^{7} \sigma^{7}\right)$. Antena con desmómero VII tan largo como ancho, subgloboso; clava antenal más estilizada. Élitros más estilizados, subelípticos. Protibias $\sigma^{\top} \sigma^{7}$ más gráciles y algo arqueadas distalmente. Lóbulo medio del edeago más robusto hacia la base y subrecto dorsalmente; mamelón apical recto, no levantado; saco interno más corto (Fig. 8C). La única hembra disponible tiene los hombros bastante marcados, romos.

Etimología. El epíteto subespecífico hace alusión a la isla de San Miguel, donde habita el insecto.

\section{Drouetius borgesi centralis ssp. nov. (Figs. 8-B, 9B, 10M-O y 11E-F)}

Localidad tíPICA: Ponta Manhenha en Pico.

Laparocerus azoricus, in Borges 1990 p. 100.

Laparocerus azoricus, in Borges 1992 p. 35 [pars].

Laparocerus azoricus, in Borges et al. 2000 p. 146 [pars].

Material examinado: Pico: Ponta Manhenha, 10 m. 1-91999, $10^{\pi}$ holotipo leg. Proyecto BALA (TFMC CO-15805). Paratipos: mismos datos de colecta $10^{\pi} 2$ 우 우 (DCA).-
Caveiro, 942 m. (N 38²6'28" W 028 13'31') $10^{\circ}$ 18-7-2004, bajo piedra en un prado, leg. A. Machado (AMC).- Henrique Maciel, $10^{\pi} 1$ ㅇ 9/13-7-2000, leg. P. Borges (AMC) GeneBank EF583349 (COII).

No paratipos: Graciosa: Pico Timão. $10^{7}$ 8-6-1988, leg. D.T. Pombo (PB) - São Jorge: Pico das Caldeirinhas 796 m, 1000 m, $20^{\pi} \sigma^{\pi} 4$ 우 ㅇ 7-1999 leg. Proyecto BALA (DCA) leg.- Pico Esperança, $1000 \mathrm{~m} 1 \sigma^{7} 1$ o 7-1999, leg. Proyecto BALA (AMC).

DiAgNosis DifERENCIAL. Talla $\sigma^{7} \sigma^{7} 6,6-8,2 \mathrm{~mm}$, 우 우 8,0-9,1 mm. Parecido a la subespecie nominotípica pero ojos mayores y rostro más corto y menos estrangulado (como en la ssp. sanctimichaelis). Élitros $\sigma^{\top} \sigma^{\pi}$ menos curvados en su tramo medio, subparalelos, hombros algo marcados. Tibias más claramente carinadas externamente, más curvadas apicalmente, algo sinuosas por dentro. Lóbulo medio del edeago menos arqueado que en la ssp. sanctimichaelis, ápice curvado hacia arriba como en la ssp. borgesi, pero sin indicio de quilla mediana (Fig. 8B).

Etimología. El epíteto subespecífico hace alusión a la posición central que ocupan las islas donde habita, en el conjunto de las Azores.

\section{Claves de determinación del género Drouetius Méquignon, 1942}

1 Metarrostro ancho de lados paralelos o ligeramente convergentes hacia delante. Punteado del pronoto abierto, los intervalos igual o mayores que el diámetro de los puntos. Ojos emplazados lateralmente a media altura de la cabeza. Procoxas alejadas del margen anterior del prosterno. Transponedor del edeago largo y de ápice progresivamente agudo, afilado

- Metarrostro estrangulado a la mitad. Punteado del pronoto muy apretado, los intervalos menores que el diámetro de los puntos. Ojos más próximos al borde de la frente. Procoxas alcanzando el margen anterior del prosterno. Transponedor del edeago corto, en forma de $\mathrm{S}$ y ápice truncado (Drouetius borgesi n. sp.)

.. 8

2 Pronoto con escamas setiformes erguidas sobresaliendo del perfil lateral, en vista dorsal. Élitros de la hembra sin hileras de setas erguidas en los intervalos impares. Transponedor del edeago muy pequeño, breve y bruscamente curvado en la base (Drouetius azoricus (Drouet, 1859)

3

- Pronoto con escamas piliformes o lanceoladas tumbadas y sin sobresalir sobre el perfil lateral, en vista dorsal Élitros de la hembra con hileras de setas erguidas a lo largo de los intervalos impares. Transponedor del edeago grande y muy largo (flagelo), ampliamente curvado en la base (Drouetius oceanicus n. sp.)

6 
3 Márgenes ventrales del rostro paralelos; los pterigios pequeños y nada sobresalientes (Terceira)

Drouetius azoricus parallelirostris n. $\mathrm{ssp}$.

- Márgenes ventrales del rostro convergentes hacia su base; los pterigios mayores y sobresalientes

.... 4

4 Pronoto de lados redondeados; las escamitas sobresalientes en el margen lateral menores, poco llamativas y limitadas a la mitad posterior Élitros lustrosos, con puntos débiles y microescultura muy superficial (Corvo y Flores) ...............

Drouetius azoricus nitens n.ssp.

- Pronoto de lados arqueados; las escamas notoriamente sobresalientes a lo largo de todo el margen lateral. Élitros brillantes, de aspecto alutáceo, microescultura bien impresa con punto foveiforme central profundo ... 5

5 Élitros con escamitas lanceoladas menores (menores de $100 \mu \mathrm{m}$ ), más anchas y muy tumbadas, (San Miguel) ......

Drouetius azoricus separandus n.ssp.

- Élitros con escamas piliformes mayores (120-140 $\mu \mathrm{m})$, levantadas e inclinadas (Faial, Graciosa, San Jorge) ...........

Drouetius azoricus azoricus (Drouet, 1859)

6 Pronoto y élitros con punteado bien marcado y revestimiento llamativo y denso en los flancos del pronoto y élitros, a base de escamas lanceoladas de color blanquecino o pajizo, algo levantadas en los hombros y ápice (Terceira)

Drouetius oceanicus oceanicus n. ssp.

- Pronoto y élitros con punteado más superficial y revestimiento a base de pilosidad dorada fina, poco aparente y con unas pocas escamitas más anchas formando algunos teselas en el élitros (Faial, Graciosa, San Jorge y San Miguel)

Drouetius oceanicus tristis n.ssp.

7 Ojos uniformemente convexos, apenas salientes, de convexidad inferior al 20\%. Rostro más largo que ancho, muy estrangulado dorsalmente (Terceira)

Drouetius borgesi borgesi $\mathrm{n}$. ssp.

- Ojos algo excéntricos, más salientes, de convexidad superior al 25\%. Rostro más cuadrangular, menos estrangulado dorsalmente
8 Élitros de lados curvados, subelípticos; pilosidad en el disco más corta que en los flancos, los pelitos apenas alcanzan la base del siguiente. Ápice del edeago, visto de perfil, prolongado en un pequeño mamelón recto (San Miguel) ......... Drouetius borgesi sanctimichaelis n. ssp.

- Élitros de lados subparalelos en su tramo medio; pilosidad uniforme y más largas, los pelitos solapándose más. Ápice del edeago, visto de perfil, curvado hacia arriba (Pico, San Jorge y Graciosa) ...... Drouetius borgesi centralis n. ssp.

\section{Corología y ecología}

El género Drouetius es endémico de las Azores y se ha encontrado en todas las islas salvo en Santa María, la más antigua. Esta ausencia es sorprendente toda vez que en el resto de bosque natural que allí queda, aunque muy reducido y bastante alterado, perviven especies relícticas de otros coleópteros, como Tarphius (Colydiidae), Cedrorum (Carabidae) o Crotchiella (Cerambycidae). Es posible que Drouetius se haya extinguido en esta isla o que, simplemente, no se haya prospectado convenientemente.

De hecho, la distribución de las especies por islas que aquí se presenta (Tabla 3 ) se ha de considerar provisional.

Existen tres líneas filéticas claras, reconocidas aquí como especies independientes, y es muy posible que se hayan originado por radiación adaptativa, pues las tres son simpátricas al menos en San Jorge, Graciosa, Terceira y San Miguel. A su vez, cada una de estas líneas parece haberse diferenciado alopátricamente según las islas, aunque la falta de material más copioso ha permitido caracterizar morfológicamente solo algunas de estas subespecies. El esquema actual es como sigue:

Tabla 3.- Distribución insular del género Drouetius en las Azores. Edades de las islas tomadas de Azevedo \& Portugal Ferreira (2006). A, O y B representan a D. azoricus, D. oceanicus y D. borgesi, respectivamente.

Tabla 3.- Island distribution of the genus Drouetius in the Azores. Island ages in million years taken from Azevedo \& Portugal Ferreira (2006). A, O and B stand for D. azoricus, D. oceanicus and D. borgesi, respectively.

\begin{tabular}{|c|c|c|c|c|c|c|c|c|c|}
\hline & COR & FLO & FAI & PIC & SJO & GRA & TER & SMI & SMA \\
\hline D. azoricus nitens & A & A & & & & & & & \\
\hline D. azoricus azoricus & & & A & & A & A & & & \\
\hline D. azoricus parallelirostris & & & & & & & A & & \\
\hline D. azoricus separandus & & & & & & & & A & \\
\hline D. oceanicus tristis & $\mathrm{O}$ & & $\mathrm{O}$ & & $\mathrm{O}$ & $\mathrm{O}$ & & $\mathrm{O}$ & \\
\hline D. oceanicus oceanicus & & & & & & & $\mathrm{O}$ & & \\
\hline D. borgesi centralis & & & & B & B & B & & & \\
\hline D. borgesi borgesi & & & & & & & B & & \\
\hline D. borgesi sanctimichaelis & & & & & & & & B & \\
\hline Edad isla en millones de años & 0,71 & 2,15 & 0,73 & 0,25 & 0,55 & 2,50 & 3,52 & 4,01 & 8,12 \\
\hline
\end{tabular}




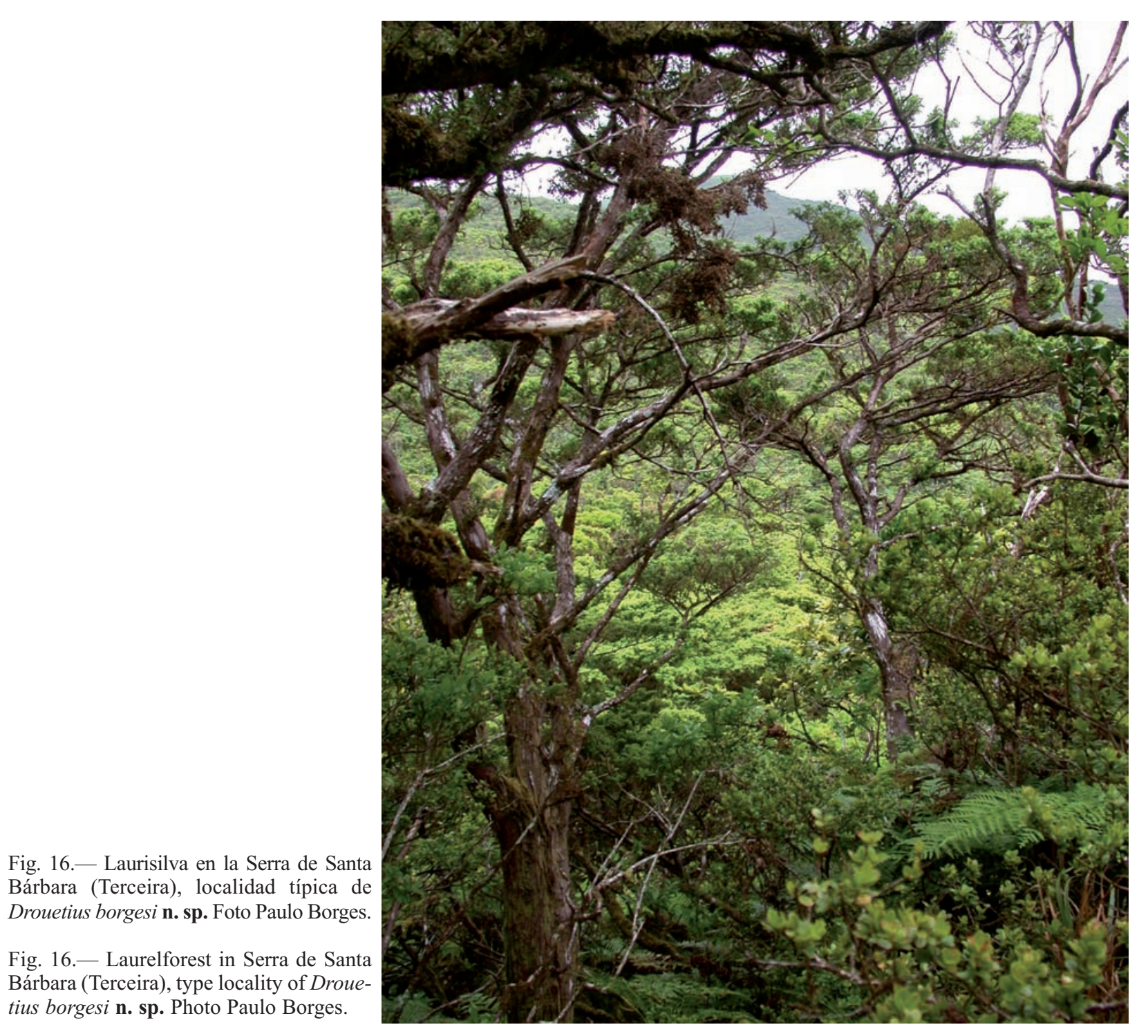

- Drouetius azoricus se extiende por siete islas, con una subpoblación muy diferenciada en Corvo y Flores, en el extremo occidental del archipiélago, y a donde no llega aparentemente $D$. borgesi. Drouetius azoricus azoricus -a falta de estudiar más ejemplares- abarca el grupo central: Faial, San Jorge y Graciosa, faltando en Pico.

Su ausencia podría explicarse por la juventud de esta isla $(<300.000$ años), pero sorprende, ya que durante las últimas glaciaciones pleistocénicas se supone que Pico estuvo unida por un istmo a Faial; el actual canal que las separa tiene profundidades que rondan los 65-100 m (Tempera, 2008). Las islas de Terceira y San Miguel, cuentan cada una con una subespecie propia.
- Drouetius oceanicus abarca las mismas islas que D. azoricus, salvo Flores, donde presumiblemente debe de existir ya que habita en Corvo. Falta igualmente en Pico y, de momento, solo se ha podido reconocer una población insular diferenciada en Terceira: D. oceanicus separandus. El material disponible de las demás islas es muy escaso.

- Drouetius borgesi es una especie bien diferenciada morfológicamente respecto de las dos anteriores, que se parecen mucho. Presenta una distribución similar a la de $D$. oceanicus, pero está presente en Pico y falta, de momento, en Faial, donde el equipo del Dr. Borges muestreó en 
2004 con trampas de caída en la vegetación natural de Caldeira, sin éxito. La subpoblación de Terceira (ssp. borgesi), es la más diferenciada y mejor conservada; le sigue la de San Miguel (ssp. sanctimichaelis), mientras que las de las restantes islas (Graciosa, San Jorge y Pico) se mantienen reunidas en un mismo taxon (ssp. centralis). Los pocos ejemplares estudiados presentan ciertas variaciones, pero su alcance es imposible de precisar a falta de más material.

Méquignon (1946) destaca la pobreza de herbívoros en las Azores, hecho que Serrano (1982) o Quartau (1982) atribuyen a la pobreza relativa de la flora. Sin embargo, de todas las islas de la Macaronesia, las Azores - colonizadas a partir de 1432- son las más extensivamente transformadas por el hombre, y resulta imposible valorar cuánto de la pobreza faunística del archipiélago obedece a factores naturales (ver introducción), y cuánto a la alteración antrópica de los hábitats. Además, la presencia de una fauna adventicia importante - cerca del 60\% de las especies son introducidas (Borges, 1992)- seguro que tampoco favorece la pervivencia de los elementos nativos. Bien es verdad, que muchas de estas especies nativas o incluso endémicas se encuentran actualmente tanto en los escasos ambientes naturales residuales, como en los antrópicos (Borges et al., 2006). No obstante, cabe suponer que esta acomodación forzada a un hábitat de sustitución no habrá sido igual para todas las especies, particularmente, para las más estenoicas.

Ante un panorama así, no es fácil inferir la ecología original de los Drouetius, si descartamos $D$. borgesi, sobre el que existe buena información. Esta especie, desconocida hasta 1997, fue colectada repetidamente durante el proyecto BALA con trampas de caída emplazadas en el suelo a lo largo de transectos en la laurisilva de Terceira (Pico do Galhardo y Serra de Santa Bárbara), entre junio y septiembre. En dicho hábitat la recolectamos de noche batiendo la intrincada vegetación (Fig. 16), obteniendo 30 ejemplares a partir de Laurus azorica, Ilex perado azorica (Aquifoliaceae), Hedychnium gardneranum* (Zingiberaceae), Diplazium caudatum (Athyriaceae) y otros helechos. En zonas de matorral o de bosque cultivado próximas a laurisilva (Algar do Carvão), apareció junto a Otiorhynchus sulcatus (Fabricius, 1775)* sobre Cryptomeria japonica* (Taxodiaceae), Rubus ulmifolius (Rosaceae), Hypericum perforatum (Hypericaceae) y helechos (en esta relación se han indicado con asterisco las especies exóticas). Parece, pues, tratarse de una especie polífaga, forestal y estival ligada a la laurisilva, donde trepa a la vegetación para alimentarse durante la noche. No obstante, unos pocos ejemplares de $D$. borgesi centralis se han capturado con trampas en prados naturales de altitud en San Jorge (800-1000 m) y obtuvimos un ejemplar a $942 \mathrm{~m}$ en Pico bajo una piedra al borde de la carretera que atraviesa un prado artificial, pero no muy lejos de restos de laurisilva. En esta isla, el Dr. Borges la ha colectado en la laurisilva dominada por Picconia azorica (Oleaceae) en Ponta Manhenha, a escasa altitud (10 m).

La información disponible sobre la ecología de Drouetius azoricus es muy pobre. Casi todas las capturas son bajo piedras, de forma ocasional. Crotch (1867) comenta que Godman la encontró abundante en San Miguel en abril de 1865, aunque no se ha podido confirmar si se trata de esta especie o de $D$. oceanicus. Sin embargo, Méquignon (1942) registra 17 exx (1 ex confirmado) colectados por Nodier en San Miguel en agosto de 1887; también agosto para los más de cien ejemplares que refiere Drouet en Faial, e igualmente abundante en agosto al fondo de la Caldera en Corvo (leg. Jules de Guerne).

Se trata pues de una especie eminentemente estival. La serie típica de $D$. azoricus parallelirostris proviene de Monte Brasil, la pequeña isleta unida a la ciudad de Angra do Heroísmo, en Terceira. La encontramos en julio, de noche, alimentándose sobre Salpichroa origanifolia (Solanacea), una planta herbácea introducida que crece en los márgenes de la pista que discurre por la parte alta de este "parque forestal" (150 m), mientras que batiendo las ramas de ejemplares de Laurus azorica, Rubus ulmifolius y Myrica faya (Myricaceae) que perviven allí entremezclados con árboles exóticos, sólo cayeron Otiorhynchus sulcatus, O. parvicollis y $O$. cribricollis, especies que por su tamaño y hábitos nocturnos, podrían considerarse competidoras potenciales de Drouetius. Con todo, la especie no parece ser forestal y aunque Borges \& Brown (2001) no la encontraron en sus muestreos en prados naturales de altura, bien podría estar vinculada a este tipo de hábitat. Los actuales pastizales de las zonas bajas y medianías de las Azores -que fueron originalmente ambientes boscosos- parecen haber ofrecido un hábitat adecuado a $D$. azoricus, tal como se deduce de las citas antiguas. Pero es posible que con la introducción de la fertilización química intensiva que ahora se practica en todos ellos, la especie haya sufrido una drástica regresión.

Para Drouetius oceanicus resulta igualmente difícil aventurar cuál era originalmente su hábitat 
natural, aunque se puede descartar el bosque húmedo. La serie típica de la subespecie tristis procede de Pico Timão, en Graciosa, donde fue colectada bajo piedras en un prado salpicado de matorral exótico, sobre los $300 \mathrm{~m}$. Sin embargo, las capturas más abundantes de los años 40 y 50 del siglo pasado en Praia Vitoria (Terceira) y Pasteleira o Porto Pim (Faial) invitan a pensar en una posible vinculación de la especie a suelos arenosos, como es el caso en estas localidades costeras, que también son algo más xéricas. Roudier (1965) comenta que los profesores Brinck y Dahl solo encontraron cadáveres (élitros) en marzo de 1957 en Praia Vitoria (Terceira) y Porto da Boca de Ribeira (Faial) y aventura que la especie debe estar en vías de disminución, o bien desarrollarse más avanzado el verano. A nuestro entender, se trata de ambas cosas. Todas estas localidades costeras están prácticamente arruinadas por la ocupación urbana, y hemos buscado la especie sin éxito alguno.

\section{AGRADECIMIENTOS}

Este trabajo no se podría haber realizado sin la colaboración de los museos y particulares que han facilitado el estudio de sus colecciones. Mi agradecimiento expreso a todos ellos y muy especialmente al Dr. Paulo Borges, de Terceira, que puso a mi disposición todo el material recogido por el proyecto BALA. Igualmente, el Dr. Miguel Ángel Alonso-Zaragaga y el Dr. Antonio J. Velázquez de Castro han contribuido de manera especial con sus atinados comentarios. La primera campaña a las Azores, visita a museos y la parte molecular de este estudio fue financiada por la Fundación Biodiversidad (Madrid).

\section{Referencias}

Alonso-Zarazaga, M. Á. \& Lyal, C. H. C., 1999. A world catalogue of families and genera of Curculionoidea (Insecta: Coleopotera) (Excepting Scolytidae and Platypodidae). Entomopraxis. Barcelona. $315 \mathrm{pp}$

Azevedo, J. M. M. \& Portugal Ferreira, M. R., 2006. The volcanotectonic evolution of Flores Islands, Azores (Portugal). Journal of volcanology and geothermal research, 156: 90-102.

Borges, P. A. V., 1990. A checklist of the coleoptera from the Azores with some systematic and biogeographical comments. Boletim do Museu Municipal do Funchal, 42(220): 137-140.

Borges, P. A. V., 1991. Biogeografia dos coleópteros (Insecta, Coleoptera) das Açores. Universidade dos Açores, Departamento de Ciências Agrárias. Angra do Heroísmo. 102 pp.

Borges, P. A. V., 1992. Biogeography of the Azorean coleoptera. Boletim do Museu Municipal do Funchal, 44(237): 5-76.
Borges, P. A. V., 1999. A list of arthropod species of sown and semi-natural pastures of three Azorean islands (S. Maria, Terceira and Pico) with some conservation remarks. Açoreana, 9(1): 12-34.

Borges, P. A. V., Cunha, R., Gabriel, R., Martins, A. F., Silva, L. \& VIEIRA, V. (eds.). 2005. A list of the terrestrial fauna (Mollusca and Arthropoda) and flora (Bryophyta, Pterydophyta and Spermatophyta) from the Azores. Direcção Regional do Ambiente \& Universidade dos Açores. Angra do Heroísmo e Ponta Delgada. 317 pp.

Borges, P. A. V., Lobo, J. M., AzEVEdo, E. B. DE, GASPAR, C. S., Melo, C. \& Nunes, L. V., 2006. Invasibility and species richness of island endemic arthropods: a general model of endemic vs exotic species. Journal of Biogeography, 33: 169-187.

Borges, P. A. V. \& SERRANO, A. R. M., 1989. New records of the coleopterous fauna (Insecta, Coleoptera) from the Azores. Boletim do Museu Municipal do Funchal, 41(209): 5-24.

Borges, P. A. V., Serrano, A. R. M. \& Quartau, J. A., 2000. Ranking the Azorean natural forest reserves for conservation using their endemic arthropods. Journal of Insect Conservation, 4: 129-147.

Crotch, G. R., 1867. On the Coleoptera of the Azores. Proceedings of the Zoological Society of London, 1867: 359-391.

Damoiseau, R., 1967. Monographie des Coléoptères Brentidae du Continent Africain. Annales du Musée royal de l'Afrique Central. Série in 8vo (Sciences Zoologiques), 1: 1-507.

Drouet, H., 1859. Coléoptères açoréens. Revue et Magasin de Zoologie, Paris, $2^{\text {éme }}$ série, 7: 243-259.

Godman, F. D. C., 1870. Natural history of the Azores or Western Islands. John van Voorst. London. 358 pp.

LACORDAIRE, T. H., 1863. Histoire naturelle des Insectes. Genera des Coléoptères. T. VI. Curculionides. Librairie Encyclopédique de Roret. Paris. 594 pp.

LonA, C., 1938. Curculionidae: Otiorhynchinae III. In: Junk, W. \& Schenkling, S. (eds.). Coleopterorum Catalogus. Dr. W. Junk. Gravenhage: 413-600.

Machado, A., 2006. The type material of the species of Laparocerus Schönherr, 1834 (Coleoptera, Curculionidae, Entiminae). Journal of Natural History, 40(35-37): 2001-2055.

Machado, A., López, M., Almeida, T. \& Hernández, M. 2008. Mitochondrial DNA phylogenetic analysis of the genus Laparocerus (Coleoptera, Curculionidae, Entiminae). I. The Madeiran clade. Zoologica Scripta, 37: 415-427.

MÉQuignon, A., 1942a. Voyage de MM. L. Chopard et A. Méquignon aux Açores (Août-Septembre 1930). XIII. Diagnoses de coléoptères nouveaux. Bulletin de la Société entomologique de France, 48(1): 9-11. 
MÉQuignon, A., 1942b. Voyage de MM. L. Chopard et A. Méquignon aux Açores (Août-Septembre 1930). XIV. Catalogue des coléoptères açoréens. Annales de la Société entomologique de France, 111: 1-66.

NyLANDER, J. A. A., 2004. MrModeltest 2.2. Evolutionary Biology Centre, Uppsala University. Programa distribuido por el autor.

Oberprieler, R. G., Marvaldi, A. E. \& Anderson, R. S., 2007. Weevils, weevils, weevils everywhere. Zootaxa, 1228: 491-520.

QUARTAU, J. A., 1982. A preliminary faunistic analysis of the Cidadellidae (Homoptera, Auchenorrhyncha) of the Azores. Boletim da Sociedade Portuguesa de Entomología, 7(Supl. A): 145-149.

RonQuist, F. \& Huelsenbeck, J. P., 2003. MrBayes 3: Bayesian phylogenetic inference under mixed models. Bioinformatics, 19: 1572-1574.

ROUDIER, A., 1965. Coléoptères curculionides des Açores et de Madère. Report No. 40 from the Lund University Expedition in 1957 to the Azores and Madeira. Boletim do Museu Municipal do Funchal, 29(79): 37-49.

SERrAno, A. R. M., 1982. Contribuição para o conhecimento do povoamento, distribuição e origem dos coleópteros do arquipélago dos Açores (Insecta, Coleoptera). Boletim do Museu Municipal do Funchal, 34(147): 67-104.

SHARP, D., 1918. Studies in Rhynchophora. IV. A preliminary note on the male genitalia. Transactions of the Entomological Society of London, 1918(I, II): 9221.

Tempera, F., 2008. Benthic habitats of the extended Faial island shelf and their relationship to geologic, oceanographic and infralittoral biologic features. $\mathrm{PhD}$ thesis. University of St. Andrews. $321 \mathrm{pp}$.

Thompson, J. D., Higgins, D. G. \& Gibson, T. J., 1994. Clustal W: improving the sensitivity of progressive multiple sequence alignment through sequence weighting, position-specific gap penalties and weight matrix choice. Nucleic Acids Research, 22: 46734680.
THOMPSON, R. T., 1989. Terminology of the spermatheca - a protest. Curculio, 26: 3-4.

THOMPSON, R. T., 1992. Observations on the morphology and classification of weevils (Coleoptera, Curculionoidea) with a key to major groups. Journal of Natural History, 26: 835-891.

UytTenboogant, D. L., 1940. Einiges über Azorische Rüsselkäfer. Entomologische Berichte, Amsterdam, 10: 265-271.

Uyttenboogaart, D. L., 1947. Coleoptera (excl. Staphylinidae et Hydrophilidae) von den Azoren und Madeira. Iter entomologicum et botanicum ad Insulas Madeiram et Azores anno 1938 a Richard Frey, Ragnar Storå et Carl Cedercreutz factum. No. 12. Societas Scientiarum Fennica, Commentationes Biologicae, 8 (12): 1-15.

WinkLER, A. (ed.), 1924-1932. Catalogus coleopterorum regionis palaearcticae. Albert Winkler. Wien. $1698 \mathrm{pp}$.
Recibido, 24-IX-2008 Aceptado, 13-V-2009 Publicado, 29-VI-2009 